\title{
Cell layer-specific expression of the B-class MADS-box gene PhDEF drives petal tube or limb development in petunia flowers
}

Chopy M. ${ }^{1,2}$, Cavallini-Speisser Q. ${ }^{1}$, Chambrier P. ${ }^{1}$, Morel P. ${ }^{1}$, Just J. ${ }^{1}$, Hugouvieux V. ${ }^{3}$, Rodrigues Bento S. ${ }^{1}$, Zubieta C. ${ }^{3}$, Vandenbussche M. ${ }^{1, *}$ and Monniaux M. ${ }^{1, *}$

${ }^{1}$ Laboratoire de Reproduction et Développement des Plantes, Université de Lyon, ENS de Lyon, UCB Lyon 1, CNRS, INRAE, 69007 Lyon, France.

${ }^{2}$ Current address: Institute of Plant Sciences, University of Bern, Altenbergrain 21, Bern, CH-3013, Switzerland.

${ }^{3}$ Laboratoire de Physiologie Cellulaire et Végétale, Université Grenoble-Alpes, CNRS, CEA, INRAE, IRIG-DBSCI, 38000 Grenoble, France.

* Authors for correspondence: michiel.vandenbussche@ens-lyon.fr, marie.monniaux@ens-lyon.fr 


\section{ABSTRACT}

Floral homeotic MADS-box transcription factors ensure the correct development of floral organs with all their mature features, i.e. organ shape, size, colour and cellular identity. Furthermore, all plant organs develop from clonally-independent cell layers, deriving from the meristematic epidermal (L1) and internal (L2 and L3) layers. How cells from these distinct layers acquire their floral identities and coordinate their growth to ensure reproducible organ development is unclear. Here we study the development of the Petunia $x$ hybrida (petunia) corolla, which consists of five fused petals forming a tube and pigmented limbs. We present petunia flowers expressing the B-class MADS-box gene $P h D E F$ in the epidermis or in the mesophyll of the petal only, that we called wico and star respectively. Strikingly, the wico flowers form a very small tube while their limbs are almost normal, and the star flowers form a normal tube but very reduced and unpigmented limbs. Therefore, the star and wico phenotypes indicate that in the petunia petal, the epidermis mainly drives limb growth and pigmentation while the mesophyll mainly drives tube growth. As a first step towards the identification of candidate genes involved in specification of petal layer identities and tube/limb development, we sequenced the star and wico whole petal transcriptome at three developmental stages. Among downregulated genes in star petals, we found the major regulator of anthocyanin biosynthesis ANTHOCYANIN 1 (AN1), and we showed that, in vitro, PhDEF directly binds to its terminator sequence, suggesting that it might regulate its expression. Altogether this study shows that layer-specific expression of $P h D E F$ drives petunia tube or limb development in a highly modular fashion, which adds an extra layer of complexity to the petal development process. 


\section{INTRODUCTION}

All plant aerial organs derive from clonally-distinct layers, named L1, L2 and L3 in the shoot apical meristem (SAM) (Satina et al., 1940). Within the L1 and L2 layers, cells divide anticlinally, thereby maintaining a clear layered structure in all aerial organs produced by the SAM (Meyerowitz, 1997; Stewart and Burk, 1970; Scheres, 2001). Already at the meristematic stage, cell layers express different genes and thereby have their own identity (Yadav et al., 2014). For flower formation, floral organ identity will be appended on top of layer identity by the combinatorial expression of homeotic floral genes, most of which are MADS-box genes (Coen and Meyerowitz, 1991; Schwarz-Sommer et al., 1990). How these master floral regulators specify all floral organ features, such as organ size, shape, pigmentation, and cellular characteristics, while maintaining layer-specific features, remains unknown.

Petals are often the most conspicuous organs of the flower, and they display a tremendous diversity in size, shape and pigmentation across flowering plants (Moyroud and Glover, 2017). Floral organ identity is specified by a combination of A-, B- and C-class identity genes as proposed by the classical ABC model established on Arabidopsis thaliana (Arabidopsis) and Antirrhinum majus (snapdragon), and B-class genes are particularly important for petal identity (Coen and Meyerowitz, 1991; Schwarz-Sommer et al., 1990). B-class proteins, belonging to MADS-box transcription factors, are grouped in the DEF/AP3 and the GLO/PI subfamilies, named after the snapdragon/Arabidopsis B-class proteins DEFICIENS/APETALA3 and GLOBOSA/PISTILLATA (Purugganan et al., 1995; Theißen et al., 1996). These proteins act as obligate heterodimers consisting of one DEF/AP3 and one GLO/PI protein, and this complex activates its own expression for maintenance of high expression levels all along petal and stamen development (Tröbner et al., 1992). In petunia, gene duplication has generated four B-class genes, namely PhDEF and PhTM6 belonging to the DEF/AP3 subfamily, and PhGLO1 and PhGLO2 belonging to the GLO/PI subfamily (Vandenbussche et al., 2004; Rijpkema et al., 2006; van der Krol et al., 1993; Angenent et al., 1992). Mutating the two members of each subfamily (phdef phtm6 or phglo1 phglo2 double mutants) produces a classical B-function mutant phenotype with homeotic transformation of petals into sepals and stamens into carpels (Vandenbussche et al., 2004; Rijpkema et al., 2006). Additionally, gene copies within the $D E F / A P 3$ subfamily have subfunctionalized: while $P h D E F$ exhibits a classical B-class expression pattern largely restricted to developing petals and stamens, atypically PhTM6 is mainly expressed in stamens and carpels, and its upregulation depends on the petunia C-function genes (Rijpkema et al., 2006; Heijmans et al., 2012). As a consequence, the single phdef mutant displays a homeotic conversion of petals into sepals, while the stamens are 
unaffected due to redundancy with PhTM6 (Rijpkema et al., 2006). The petunia phdef mutant is therefore an interesting model to study the mechanism of petal identity specification alone since it displays a single-whorl complete homeotic transformation, which is quite rare for floral homeotic mutants that generally show defects in two adjacent whorls.

Flowers from the Petunia genus develop five petals, that arise as individual primordia and fuse congenitally. Mature petals are fully fused and the corolla is organized in two distinct domains: the tube and the limbs. Variation in the relative size of these subdomains of the corolla are observed between wild species of Petunia, where flowers with a long tube grant nectar access to longtongued hawkmoths or hummingbirds, while wide and short tubes are easily accessible to bees (Galliot et al., 2006). The short- and long-tube species cluster separately on a phylogeny made from 20 wild Petunia species, and the short-tube phenotype is likely the ancestral one (Reck-Kortmann et al., 2014). Pollinator preference assays and field observations have confirmed that tube length and limb size are discriminated by pollinators and thereby might play a role in reproductive isolation, together with multiple other traits of the pollination syndromes such as limb pigmentation (Venail et al., 2010; Hoballah et al., 2007; Galliot et al., 2006).

Although the petunia petal tube and limbs seem to play important ecological roles, the mechanisms driving their development are mostly unknown. Tube and limb develop as relatively independent entities in flowers from the Solanaceae family, to which petunia belongs: for instance, tube length and limb width are uncorrelated traits in intra-specific crosses performed in Nicotiana and Jaltomata (Bissell and Diggle, 2008; Kostyun et al., 2019). Moreover, tube and limb identities can be acquired independently: this is strikingly observed in the petunia blind mutant, a partial Aclass mutant, that forms an almost wild-type tube topped by functional anthers (Cartolano et al., 2007). Apart from the petal identity genes, the molecular players involved in petunia tube or limb growth are mostly unknown. General growth factors affect petal development as a whole (both tube and limbs) together with other vegetative or reproductive traits (Vandenbussche et al., 2009; Terry et al., 2019; Brandoli et al., 2020), but to our knowledge, only one gene has been found to specifically affect growth of one subdomain of the petal: downregulation of PhEXP1, encoding an $\alpha$-expansin expressed in petunia petal limbs, leads to a specific decrease in limb area without affecting tube length (Zenoni et al., 2004). Therefore, the mechanisms of petunia tube and limb growth remain to be fully explored. In contrast, the genetic and molecular bases of petunia petal pigmentation are extremely well characterized, thanks to the plethora of mutants that have been isolated over decades of breeding and research (Bombarely et al., 2016; Tornielli et al., 2009). Petunia limb pigmentation is mainly due to the presence of anthocyanins in the vacuole of epidermal cells. Briefly, the earliest steps of anthocyanin production are ensured by a MBW 
regulatory complex composed of ANTHOCYANIN1 (AN1, a $\underline{b} H L H$ transcription factor), AN11 (a

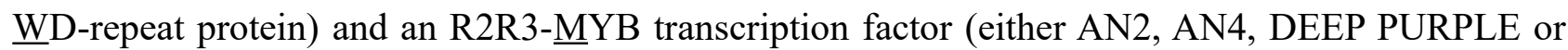
PURPLE HAZE), which drives the expression of anthocyanin biosynthesis enzymes and proteins involved in vacuolar acidification of epidermal cells (Koes et al., 2005; Albert et al., 2011). How this pathway is activated, after regulators such as PhDEF have specified petal identity, has not been determined so far.

In this work, we present petunia flowers with strongly affected tube or limb development, that we respectively named wico and star, and that spontaneously arose from plants mutant for $P h D E F$. We provide genetic and molecular evidence that these contrasting flower phenotypes both are periclinal chimeras, resulting from the layer-specific transposon excision of the phdef-151 allele, restoring $P h D E F$ activity either in the epidermis or in the mesophyll of the petal. The star and wico phenotypes indicate that in the petunia petal, the epidermis mainly drives limb growth and pigmentation while the mesophyll mainly drives tube growth. This is seemingly different from previous studies in Antirrhinum majus flowers, where def periclinal chimeras led the authors to conclude that epidermal $D E F$ expression was making a major contribution to petal morphology (Perbal et al., 1996; Vincent et al., 2003; Efremova et al., 2001). We characterized in detail the star and wico petal phenotypes at the tissue and cellular scale, and found evidence for non-cellautonomous effects affecting cell identity between layers. We sequenced the total petal transcriptome from wild-type, wico and star flowers at three developmental stages, and we found that a large proportion of the genes involved in anthocyanin production were downregulated in star petal samples, as could be expected from their white petals. We further showed that PhDEF directly binds in vitro to the terminator region of $A N 1$, thereby possibly regulating its expression and triggering the early steps of limb pigmentation. Our results and our unique star and wico material promise to improve our understanding of tube and limb development in petunia, and address the broader question of how organ identity and cell layer identity superimpose during organ development. 


\section{Results}

\section{Spontaneous appearance of two phenotypically distinct classes of partial revertants from the phdef-151 locus}

Previously described null alleles for the PhDEF gene (also named GP or $p M A D S 1$ ) were obtained by either ethyl methanesulfonate (EMS) mutagenesis (de Vlaming et al., 1984; Rijpkema et al., 2006) or by $\gamma$-radiation (van der Krol et al., 1993). In our sequence-indexed dTphl transposon mutant population in the W138 genetic background (Vandenbussche et al., 2008), we identified a new mutant allele of $P h D E F$, named phdef-151, referring to the $d T p h 1$ insertion position 151 bp downstream of the ATG in first exon of the PhDEF gene, disrupting the MADS-domain. As observed for previously identified phdef null alleles, phdef-151 flowers display a complete homeotic conversion of petals into sepals (Fig. 1A-D). phdef-151 is thus very likely a null mutant allele.

While growing homozygous phdef-151 individuals during several seasons, we repeatedly observed the spontaneous appearance of inflorescence side branches that developed flowers with a partial restoration of petal development (Fig. 1E-H, Fig. S1). Interestingly, these partially revertant flowers could be classified as belonging to either one of two contrasting phenotypic classes, that we named star and wico. For both phenotypic classes, we obtained more than 10 independent reversion events. The star flowers (Fig. 1E, F), named in reference to their star-shaped petals, grow an elongated tube similar to wild-type flowers, but their limbs are underdeveloped: they appear to mainly grow around the mid-vein with reduced lateral expansion, hence losing the typical round shape of wild-type limbs. Moreover, they do not display pigmentation, apart from occasional red sectors (Fig. S1B-F). We quantified these changes in flower morphology and found that total limb area was reduced almost 5-fold in star flowers (Fig. 1K). In contrast total tube length was only slightly reduced in star as compared to wild type (Fig. 1J), and this was mainly due to a reduction in length of domain D1, corresponding to the part of the tube fused with stamens (as defined in (Stuurman et al., 2004), Fig. 1I), while length of the rest of the tube (domain D2) remained unchanged (Fig. 1J, Fig. S2). As a result, the ratio between limb area and tube length, which we use as a simple measure for overall corolla morphology, is reduced about 4-fold in star flowers as compared to wild type (Fig. 1L). The wico flowers, named after their wide corolla, grow roundshaped and pigmented limbs while their tube remains very small (Fig. 1G, H). Limb pigmentation ranged from pink to bright red, and green sepaloid tissue was observed around the mid-veins, especially on the abaxial side of the petals (Fig. S1H-P). Total tube length was reduced about 3-fold in wico flowers, with domain D1 being absent since stamens were totally unfused to the tube (Fig. 
S2), while domain D2 was significantly reduced in size (Fig. 1J). Limb area was also about 2-fold reduced in wico as compared to wild type flowers (Fig. 1K), but the ratio between limb area and tube length was higher than in wild type (Fig. 1L), indicating the larger contribution of limb tissue to total corolla morphology in wico. In summary, the star flowers form an almost normal tube but small, misshaped and unpigmented limbs, while the wico flowers form almost normally shaped and pigmented limbs but a tube strongly reduced in length. These contrasting phenotypes suggest that tube and limb development can be uncoupled in petunia flowers, at least to some degree.

\section{The star and wico flowers result from excision of the $d T p h 1$ transposon from the phdef-151 locus}

Reversion of a mutant phenotype towards a partial or a complete wild-type phenotype is classically observed in unstable transposon insertion mutant alleles. In the petunia W138 line from which phdef-151 originates, the dTph1 transposon is actively transposing (Gerats et al., 1990). We assumed therefore that the star and wico flowers were caused by the excision of $d T p h 1$ from the PhDEF locus. $d T p h 1$ transposition is generally accompanied by an 8-bp duplication of the target site upon insertion, and excision can have various outcomes depending on the length and nature of the remaining footprint (van Houwelingen et al., 1999). Hence we first hypothesized that the distinct star and wico phenotypes were caused by different types of alterations of the PhDEF coding sequence after the excision of $d T p h 1$.

To test this hypothesis, we characterized the phdef-151 locus from in total 14 star and 14 wico independent reversion events. For this we extracted genomic DNA from sepals or petals of star and wico flowers, and we amplified the part of the PhDEF locus containing the $d T p h 1$ transposon with primers flanking the insertion site (Fig. 2A). All samples produced a mixture of PhDEF fragments, some containing the $d T p h 1$ transposon and some where $d T p h 1$ had been excised (Fig. 2B). We specifically sequenced the small fragments resulting from $d T p h 1$ excision in star and wico petal samples, including phdef-151 second whorl organs as a control (Fig. 2C). In phdef-151 the $d T p h 1$-excised alleles were always out-of-frame, with either 7 or 8 additional nucleotides as compared to the wild-type sequence. Due to a reading frame shift, both of these alleles are expected to produce an early truncated protein likely not functional (Fig. 2C), in line with the normal phdef mutant phenotype observed in these plants. In contrast, in both star and wico flowers we could find either wild-type sequences (found 1 time and 3 times independently in star and wico flowers respectively) or in-frame footprint alleles consisting of various additions of 6 nucleotides (alleles further named $P h D E F+6$, found 13 times and 11 times independently in star and wico flowers respectively, Fig. 2C). These last insertions are predicted to result in proteins with 2 additional 
amino-acids inserted towards the end of the DNA-binding MADS domain (Fig. 2C). Together these results demonstrate that wico and star revertant flowers depend on the presence of an in-frame def151 derived excision allele that partially restores petal development. In contrast to our initial expectations however, there was no correlation between the sequence of the locus after excision and the phenotype of the flower, and both star and wico flowers could be found with a wild-type $P h D E F$ excision allele or with an identical PhDEF+6 allele (e.g. the 6-bp GTCTGG footprint allele was frequently found both in wico and star flowers). This indicates that the phenotypic difference between the star and wico flowers cannot be explained by a differently modified $P h D E F$ sequence after $d T p h 1$ excision. Secondly, since the phdef mutation is fully recessive (Vandenbussche et al., 2004), the presence of one transposon mutant allele combined with the wild-type revertant sequence, normally should lead to wild-type flowers. Together this implied that another molecular mechanism is causing the difference between wico and star flowers.

\section{The star and wico phenotypes are not heritable}

To further explore the genetic basis of the star and wico phenotypes, we analyzed the progeny after selfing of a series of independent wico and star flowers (Table 1). Because all wico and star flowers were heterozygous at the PhDEF locus (they still carried the original transposon allele in a heterozygous state), both the original transposon allele and the in-frame footprint allele were expected to segregate independently in the progeny of these flowers. Remarkably however, neither the star nor the wico phenotypes turned out to be heritable. First of all, we found that the progeny of the wico flowers almost exclusively displayed a phdef mutant phenotype, undistinguishable from the parental phdef-151 allele. In line with that, no 6-bp footprint alleles could be detected in these plants, indicating that the in-frame wico footprint alleles were not transmitted to the progeny. This suggested that the gametes generated by the wico flowers exclusively carried the mutant phdef-151 allele, hence resulting in homozygous phdef-151 mutants in the progeny.

On the other hand, both the original transposon allele and the in-frame footprint allele were found to segregate independently in the progeny of star flowers as was expected, but despite that, the star phenotype itself was not transmitted to the progeny. The progeny of the star flowers with a $P h D E F+6$ allele yielded three different phenotypic classes (in a proportion close to 1:1:2; Table 1): plants displaying a phdef phenotype, plants having wild-type flowers, and plants carrying flowers with a wild-type architecture but with reduced pigmentation, further referred to as «pink wildtype » (Fig. S3). We genotyped the PhDEF locus in plants descendant from one star parent and carrying flowers with a wild-type architecture (Table S2). We found that all plants with a pink wildtype phenotype were heterozgyous with an out-of-frame phdef allele and an in-frame $P h D E F+6$ 
allele, while fully red wild-type flowers had in-frame $P h D E F+6$ alleles at the homozygous state. This indicates that the $\mathrm{PhDEF}$ protein with 2 additional amino acids is not $100 \%$ fully functional, as it leads to a reduction in limb pigmentation when combined with an out-of-frame allele. The fact that it can ensure normal petal development when at the homozygous state indicates that this is dosage dependent. In summary, the segregation ratio shows that the star gametes carried either the phdef-151 allele or an in-frame $P h D E F$ allele at a 1:1 ratio, and hence that the germ cells generating these gametes were heterozygous for these two alleles. Therefore, analysis of the star and wico progeny informed us about the genotype of the parental germ cells, and the non-heritability of the star and wico phenotypes suggested that these flowers were genetic mosaics.

\section{Cell layer-specific PhDEF expression correlates with the wico and star phenotypes}

Excision of $d T p h 1$ from a gene can occur at different times during plant development: if happening at the zygotic stage, then the whole plant will have a $d T p h 1$-excised allele. If excision occurs later, this will result in a genetic mosaic (chimera) with a subset of cells carrying the $d T p h 1$ insertion at the homozygous state and others having a $d T p h 1$-excised allele. This typically leads to branches or flowers with a wild-type phenotype on a mutant mother plant (supposing a recessive mutation). Furthermore, since all plant organs are organized in clonally-independent cell layers, excision can happen in one cell layer only, thereby creating a periclinal chimera, i.e. a branch or flower where cell layers have different genotypes (Frank and Chitwood, 2016; De Keukeleire et al., 2001).

Several pieces of evidence suggested that the star and wico flowers were periclinal chimeras: (1) when amplifying the PhDEF fragment spanning the $d T p h 1$ excision site, the intensity of the bands obtained from the sepal and the petal tissues were consistently different, likely reflecting the quantity of $d T p h 1$-excised fragment found in the original tissue (Fig. 2B). This suggested that in wico flowers the $d T p h 1$-excised fragment was more present in petals than in sepals, and the opposite for star flowers. Sepals generally have a much thicker mesophyll than petals, therefore the relative contribution of the epidermis (L1-derived) and mesophyll (L2-derived) tissues is different. Thus this result tended to indicate that in wico and star flowers the excision happened in the epidermal and mesophyll layers respectively. (2) The non-heritability of the star and wico phenotypes and the genotype of their germ cells suggested that L2-derived cells, to which germ cells belong, had a different genotype than L1-derived cells. For instance, we found that germ cells were homozygous mutant for phdef-151 in wico, which should result in a phdef phenotype if the epidermal tissue had the same genotype. (3) Finally, periclinal chimeras for $D E F$ were already obtained in Antirrhinum majus and were found to partially restore petal development, suggesting 
that similar processes could be at stake here (Vincent et al., 2003; Perbal et al., 1996; Efremova et al., 2001).

To investigate if the star and wico flowers were indeed the result of a layer-specific excision of $d T p h 1$ from $P h D E F$, we localized the PhDEF transcript in these flowers by in situ hybridization (Fig. 3, Fig. S4). In wild-type flowers, the PhDEF transcript is first detected in the stamen initiation domain, then shortly after in incipient stamen and petal primordia (Fig. 3A, B). At all stages observed, PhDEF expression appears quite homogeneous in all cell layers of the organs, with a stronger expression in the distal part of the petal (Fig. 3C, Fig. S4C). In star flowers, the dynamics of $P h D E F$ expression was similar to wild-type flowers, but strikingly $P h D E F$ expression was absent from the L1 and epidermis (Fig. 3D-F, Fig. S4D-F). At the petal margins, underlying layers were also devoid of PhDEF expression (Fig. 3F), which likely corresponds to the restricted petal area where cells of L1 origin divide periclinally and invade the mesophyll (Satina and Blakeslee, 1941). In wico flowers we observed the exact opposite situation to the star flowers, with PhDEF expression restricted to the L1 and epidermis, all throughout petal development (Fig. 3G-I, Fig. S4G-I). Thus the star and wico flowers are respectively the result of an early $d T p h 1$ excision event in one cell from the L2 or L1 meristematic layer, resulting in a chimeric flower expressing PhDEF only in the mesophyll (L2-derived cells) or in the epidermis (L1-derived cells) of petals. Considering the star and wico phenotypes, these results suggest that the epidermis is the main driver for limb growth, shape and pigmentation, while the mesophyll mainly drives tube growth.

\section{Non-autonomous effects of layer-specific PhDEF expression on cell identity}

Knowing the genetic basis of the star and wico phenotypes, we wondered how layer-specific $P h D E F$ expression affects the determination of cell identity, in the layer where $P h D E F$ is expressed (cell-autonomous effect) but also in the layer devoid of PhDEF expression (non-cell-autonomous effect). For this, we focused on star petals and examined the appearance of their epidermal cells by scanning electron microscopy, to compare with wild-type petals and sepals, and wico petals (Fig. 4A, B, Fig. S5C, D).

On the adaxial side of the wild-type petal, cells from the limb are round and adopt the classical conical shape found in many angiosperm petals, while cells from the tube are elongated with a central cone (Fig. 4B). In contrast, the adaxial epidermis of wild-type sepals (indistinguishable from phdef-151 second whorl organs) displays typical leaf-like features (Morel et al., 2019), with puzzle-shaped cells interspersed with stomata and trichomes (Fig. 4B). Epidermal cell shape thus appears as a good parameter to discriminate epidermal cell identity between petals and sepals. In star petal tubes, epidermal cells have a similar appearance as in a wild-type petal tube 
but are slightly less elongated (Fig. 4B, D). In contrast, cells from the adaxial side of the star limbs are domed, reminiscent of wild-type conical cells, but they appear flatter and are about 3-times larger (Fig. 4C). We occasionally observed pigmented revertant sectors on star flowers, resulting from an additional independent $d T p h 1$ excision in the epidermis, generating wild-type sectors on a star flower (Fig. S5A). These sectors allow the immediate comparison between star and wild-type epidermal cells on a single sample, confirming the difference in conical cell size, shape and colour (Fig. S5A-D). Moreover, the star limbs occasionally form trichomes on their abaxial epidermis (Fig. $\mathrm{S} 5 \mathrm{C}$ ), which is a typical sepal feature that is normally not observed on petal limbs. Altogether these observations suggest that epidermal cells from star limbs have an intermediate identity between petal and sepal cells. Since star petals do not express $P h D E F$ in their epidermis, these observations show that non-cell-autonomous effects are at stake to specify cell identity. The interpretation of these effects is summarized in Fig. S6.

In wico petals, epidermal limb cells are conical, similar to wild-type cells from the same area, although slightly bigger (Fig. 4B, C). In contrast, cells from the tube, albeit displaying similar shape than wild-type cells, are strongly reduced in length (Fig. 4B, D). This suggests that in addition to the absence of the D1 region of the tube (Fig.S2), a defect in cell elongation in the D2 region is, at least partly, responsible for overall tube length reduction in wico petals. Also, we observed after peeling the epidermis from wico petal limbs (at the base of the limbs or along the petal midveins) that the underlying mesophyll was chloroplastic, similar to a sepal mesophyll and in striking contrast with the white mesophyll of wild-type petal limbs (Fig. 4E). This suggests that mesophyll identity in wico petals in similar to the one of sepals, and hence that it is defined cellautonomously, although additional histology analyses would be required to examine cell identity in more details.

We wondered if the non-cell-autonomous effects that we observed between layers in the star petals were also influencing cell identity within a layer. The revertant sectors observed on star flowers showed a very abrupt transition between pigmented and non pigmented epidermal cells (Fig. S5B), together with a quite sharp transition in conical cell shape and size (Fig. S5C). In particular, we found a clear file of pigmented cells on a star petal and the scanning electron micrograph revealed that these cells were also conical, in stark contrast with the flat surrounding cells of the petal mid-vein (Fig. S5D). Therefore we conclude that within the epidermal layer, cell shape and pigmentation are defined cell-autonomously, suggesting that different processes are at stake for cell-cell communication between and within layers. 


\section{Transcriptome sequencing of star and wico petals}

To better understand the molecular basis for the star and wico phenotypes, we performed RNA-Seq on total petal tissue at three developmental stages, including wild-type and phdef-151 samples. We chose an early stage (stage 4 as defined in (Reale et al., 2002)) when no major difference between genotypes is visible by eye, an intermediate stage (stage 8) when tube length is at half its final size, suggesting that tube growth is still active, and a late stage (stage 12) before limbs are fully expanded, suggesting that limb growth is still active (Fig. 5A). For phdef-151 we only sequenced second-whorl sepal tissue at stage 12. Principal component analysis showed that developmental stage is the first contributor to variation in gene expression, while genotype corresponds to the second axis of variation (Fig. 5B). All samples clustered separately except wico and wild-type samples which were globally highly similar at all stages. We analyzed one-to-one differential gene expression between mutant and wild-type samples with DESeq2 (Love et al., 2014) and we found on average 5,816 deregulated genes in phdef-151, as compared to 1,853 and 1,115 deregulated genes in star and wico respectively, when averaging for all stages (Fig. 5C, Table S3). There were generally more downregulated genes than upregulated ones in mutant or chimeric genotypes, and the number of deregulated genes increased with ageing of the petal in both star and wico (Fig. 5C). A large proportion of genes (58-61\%) deregulated in star or wico samples at stage 12 were also deregulated in phdef-151 samples at the same stage (Fig. 5D), as expected since star and wico flowers are mutant for $P h D E F$ in one cell layer. Genes uniquely deregulated in star or wico flowers represented $36 \%$ of deregulated genes for each, and only $16-29 \%$ of deregulated genes were jointly deregulated in star and wico flowers, consistent with the very different phenotypes of these flowers. These proportions indicate that the star and wico phenotypes are mostly subtended by the deregulation of sets of genes also deregulated in phdef-151, together with the deregulation of a

unique set of genes set for each genotype. Altogether these transcriptomes constitute a promising dataset to identify genes involved in the establishment of petal epidermis and mesophyll identities, and in tube and limb development.

\section{PhDEF directly binds in vitro to the terminator region of $A N 1$, encoding a major regulator of petal pigmentation}

To evaluate the potential for our transcriptomic dataset to decipher the gene regulatory networks underlying petal development, we decided to focus our attention on genes involved in petal pigmentation. Indeed, the players and regulatory pathways involved in anthocyanin biosynthesis in the petal epidermis have been extremely well described but their relationship with the specifiers of 
petal identity, to whom PhDEF belongs, is so far unknown. The absence of pigmentation in star petals, the restoration of pigmentation in late revertant sectors and the phenotype of the pink wildtype flowers prompted us to investigate the direct link between $P h D E F$ expression and petal pigmentation. For this, we examined the 504 genes down-regulated in both phdef-151 and star samples (at any stage) but not deregulated in wico samples (Table S4), and we found 24 anthocyanin-related genes in this gene set (out of a total of 41 in the whole genome), which constitutes an exceptionally high enrichment for this gene function ( $p<0.001$, Fisher's exact test). In particular, we found the genes encoding the major regulators ANTHOCYANIN1 (AN1), AN2, PH4 and DEEP PURPLE, as well as many genes encoding anthocyanin biosynthesis enzymes, in this dataset. We hypothesized that, since $P h D E F$ is expressed throughout petal development, the most upstream genes in the anthocyanin production pathway might be direct targets of PhDEF. Of particular interest for us were the genes $A N 1$ and $A N 2$, encoding transcription factors taking part in the MBW regulatory complex triggering anthocyanin biosynthesis in the limbs (Spelt et al., 2000; Quattrocchio et al., 1999), whereas DEEP PURPLE is mostly involved in tube pigmentation (Albert et al., 2011), and PH4 in vacuolar acidification of petal epidermal cells but has no role in anthocyanin production (Quattrocchio et al., 2006). Therefore, we aimed to test if PhDEF could be a direct activator of $A N 1$ or $A N 2$ expression.

We first attempted to predict PhDEF binding on the genomic sequences of $A N 1$ and $A N 2$. For this, we used the high-quality transcription factor (TF) binding profile database Jaspar (Fornes et al., 2020; Sandelin et al., 2004), using position weight matrices for each TF to compute relative binding scores that should reflect in vitro binding preferences (Stormo, 2013). The exact DNAbinding specificity of PhDEF has not been characterized, but only the one of its Arabidopsis homologs AP3 and PI (Riechmann et al., 1996b). Therefore, since PhDEF DNA-binding specificity might be slightly different to those of AP3 and PI, we decided to predict binding for all MADS-box TFs available in Jaspar 2020, accounting for 23 binding profiles (Fornes et al., 2020). This approach should identify high-confidence CArG boxes (the binding site for MADS-box proteins), and we still payed a special attention to AP3 and PI predicted binding sites (Fig. 6). As a validation of this strategy, we analyzed the genomic sequence of $P h D E F$ and found a high-confidence CArG box in the $P h D E F$ promoter (visible by the presence of good predicted binding sites for several MADSbox proteins and therefore appearing as a clear black line in Fig. 6A, and indicated by a red arrow), also predicted to be a high-affinity binding site for both AP3 and PI, lying in a region shown to be important both for AP3 petal-specific expression and for its auto-activation in Arabidopsis, and extremely conserved between distantly-related flowering plants (Wuest et al., 2012; Hill et al., 1998; Rijpkema et al., 2006). We next applied this predictive approach to the genomic sequences of 
$A N 1$ and $A N 2$. The genomic region of $A N 1$ appears to be a good binding environment for MADSbox proteins, with several high-confidence CArG boxes predicted (Fig. 6B). In particular, we predicted a binding site $(A N 1-b s 1)$ with a very high score, for all MADS-box proteins and for AP3 and PI in particular, in the terminator region of the AN1 gene. In contrast, in the genomic region of AN2 we found only sites with moderate binding scores (Fig. S7), therefore we decided not to investigate this gene any further.

To determine if $\mathrm{PhDEF}$ could indeed bind to $A N 1-b s 1$ and potentially regulate $A N 1$ expression, we performed gel shift assays using in vitro translated PhDEF and/or PhGLO1 proteins (Fig. 6C). We found that, when incubating a 60-bp fragment containing AN1-bs 1 in its center with either PhDEF or PhGLO1, no shift in migration was visible, meaning that neither protein could bind to this site alone. However when incubating AN1-bs 1 with both PhDEF and PhGLO1 proteins, we observed a clear shift in migration, consistent with the obligate heterodimerization of these proteins for DNA binding (Riechmann et al., 1996a). A control 60-bp fragment named AN1-bs2, also located in the $A N 1$ terminator region but predicted to have a very low binding score (relative score under 0.8 both for AP3 and PI), was indeed not bound by the PhDEF + PhGLO1 proteins, showing that our assay was specific. Therefore PhDEF, when dimerized with PhGLO1, is able to bind to a putative regulatory region in $A N 1$, suggesting that it might regulate $A N 1$ expression. Although additional assays are needed to validate this binding in vivo and the regulatory action of PhDEF + PhGLO1 on $A N 1$, this constitutes to our knowledge the first evidence of a putative direct link between petal identity regulators and petal pigmentation. 


\section{Discussion}

In this work, we identified periclinal chimeras expressing the B-class MADS-box gene $P h D E F$ in different cell layers of the flower. This layer-specific expression resulted in the development of subdomains of the petal only, showing that epidermal PhDEF expression drives limb development while its expression in the mesophyll drives tube development.

\section{Contribution of cell layers to mature petunia petals}

The shoot apical meristem (SAM) of all flowering plants is organized in three independent layers. Generally, it is assumed that L1-derived cells form the epidermis, L2-derived cells produce the mesophyll and sub-epidermal tissue, and L3-derived cells generate the ground tissues (inner mesophyll, vasculature, pith of the stem). However, there is variation to this general pattern between organs; for instance Arabidopsis sepals, stamens and carpels derive from all 3 layers, while petals derive from the L1 and L2 layers only, although they are vascularized (Jenik and Irish, 2000). Moreover, the contribution of cell layers can vary between the same organ in different species: for instance Datura stramonium (Datura) petals are derived from all 3 layers, in contrast to Arabidopsis (Satina and Blakeslee, 1941). Finally, even in one organ from a single species, cell layer contribution is not always homogeneous in different parts of the organ: in Datura petals, the L3 only participates to the vasculature at the base of the organ, and the L1 invades the mesophyll at the petal edges (Satina and Blakeslee, 1941).

In fact, the contribution of cell layers to mature organ organization can only be strictly assessed by clonal analysis, where one follows cell lineage using trackable cell-autonomous markers. In petunia, no clonal analysis has been performed so far, hence one can only assume which cell layers participate to petal development based on clonal analyses performed in closely-related species. In Datura, member of the Solanaceae family like petunia, periclinal chimeras induced by colchicine treatment and refined histological observations have provided a detailed clonal analysis for cell layers in floral organs (Satina and Blakeslee, 1941). The first visible event of petal initiation is a periclinal cell division from the L2 layer, and further growth of the petal depends primarily on cell divisions from the L2, both anticlinal and periclinal. The L3 layer only contributes to the vascular tissue at the very base of the petal. L1-derived cells form the epidermis by anticlinal divisions, except at the petal edges where periclinal divisions are observed, leading to L1-derived cells invading the mesophyll. Hence, the Datura petal is formed by all 3 layers with a major contribution of the L1 and L2 layers, and a relative enrichment in L1-derived cells (by thinning of the mesophyll) as we progress from the base towards the tip of the petal. In this work we 
hypothesized that the petunia petal is formed similarly. Consistently, we only obtained two phenotypic classes, star and wico, suggesting that L3-specific PhDEF expression probably might only lead to a phdef mutant phenotype.

\section{Different cell layers drive tube and limb growth}

The star and wico phenotypes revealed that in petunia petals, the epidermis is the main driver for limb growth while the mesophyll is the main driver for tube growth. Kutschera and others proposed the epidermal-growth-control theory (Kutschera and Niklas, 2007; Kutschera et al., 1987), where the epidermis is under tension and restricts growth from the inner tissues; therefore, the inner tissues drive organ growth but the epidermis determines the final size of the organ. This theory has been based on physical experiments performed on the shoot from several organisms: inner tissues expand when they are separated from the epidermis that retracts. However, this is opposed by genetic evidence suggesting that the epidermis can also be an active driver of shoot growth, and that signaling between layers coordinates growth at the organ level (Savaldi-Goldstein et al., 2007). Moreover, seemingly opposing conclusions have been drawn using different mutants and genetic systems (Savaldi-Goldstein and Chory, 2008), leading to the idea that any layer could be driving organ growth, depending on the species, the organ or the gene studied. In the case of the petunia petal, it is not entirely surprising that the epidermis would be the active driver of limb growth, since the limb mesophyll tissue is thin and lacunous. In particular, petal edges whose mesophyll tissue is L1-derived, can only grow if L1-derived cells are actively expanding or dividing. The fact that the tube growth is L2-driven is consistent with its tissue architecture (large mesophyll cells with less lacunes than in the limbs) and as such, it behaves more like a shoot.

Observing these apparently conflicting growth behaviours, one may wonder how general our observations are. In Antirrhinum majus (Antirrhinum) and Arabidopsis, periclinal chimeras for orthologs of PhDEF ( $D E F$ and AP3 respectively) or PhGLO1/PhGLO2 (GLO and PI respectively) have been previously obtained (Perbal et al., 1996; Vincent et al., 2003; Efremova et al., 2001; Bouhidel and Irish, 1996; Jenik and Irish, 2001). In Antirrhinum, expression of DEF only in the L1 layer largely restores petal development, particularly in the limbs, in contrast to the L2/L3 specific $D E F$ or GLO expression which causes reduced limb growth (Perbal et al., 1996; Vincent et al., 2003; Efremova et al., 2001). Petals are fused into a tube in Antirrhinum flowers, but the tube is much more reduced than in petunia, hence conclusions on tube length restoration in the chimeras were not drawn by the authors. However, in light of our results, it is clear that Antirrhinum chimeras expressing $D E F$ or $G L O$ in the L2/L3 layers restore tube development to a higher degree than limb 
development, similar to what we observed. In Arabidopsis that has simple and unfused petals, petal shape and size were never fully restored when $A P 3$ was expressed in one cell layer only (Jenik and Irish, 2001); in contrast epidermal expression of PI was sufficient to restore normal petal development (Bouhidel and Irish, 1996). Therefore, it seems that epidermis-driven limb growth and mesophyll-driven tube growth is a shared property between petunia and Antirrhinum petals. We could thus infer that this property applies to the whole clade of euasterids I to which the two species belong. Interestingly, euasterids mainly form flowers whose petals are fused into a tube, with a likely single origin for petal fusion (Zhong and Preston, 2015), suggesting the attractive but highly speculative hypothesis that petal fusion and layer-driven growth of tube vs. limbs could have arisen simultaneously.

\section{Autonomous and non-autonomous effects of $P h D E F$ expression on petal traits}

Our study revealed that petal traits were affected differently by layer-specific $P h D E F$ expression (Fig. S6). For instance, epidermal pigmentation is a clearly autonomous trait, since star petals are not pigmented except when wild-type revertant sectors arise. On the contrary, epidermal cell shape appears to behave as a partially autonomous trait since star epidermal cells are domed, but larger and flatter than wild-type conical cells. Finally, organ size and shape are specified nonautonomously in sub-domains of the petal: PhDEF expression in the L1 or L2 is sufficient to specify correct shape of the limbs or correct size and shape of the tube respectively, suggesting that in these petal domains, layer-specific PhDEF expression is sufficient to signal cells from the other layer to grow normally. The mechanisms for this inter-layer communication remain unknown. We were not able to detect PhDEF protein localization in the star and wico flowers so far, therefore we do not know if the PhDEF protein itself might be moving between layers, which would be the simplest mechanistic explanation for the non-autonomous traits that we observe. Indeed, in Antirrhinum petals expressing $D E F$ in the L2/L3 layers, the DEF protein was found in small amounts in the epidermis (Perbal et al., 1996). In contrast, Arabidopsis AP3 and PI proteins are unable to move between cell layers (Urbanus et al., 2010). In any case, even if the PhDEF protein moves between layers in our chimeric flowers, it is likely to be in small amounts only, otherwise both flower types would have a wild-type phenotype. Therefore, it is unlikely to be the reason for tube and limb correct development in the star and wico flowers. Alternatively, the non-autonomous effects that we observed might be triggered by mechanical signals transmitted between layers. For instance, in star flowers normal growth of the mesophyll could merely drag along epidermal cells, since cells are connected by their cell walls, which could be sufficient to trigger their expansion and division. More specifically, conical cells are shaped by a circumferential microtubule arrangement 
controlled by the microtubule-severing protein KATANIN, and altering this arrangement affects conical cell shape (Ren et al., 2017). Microtubule arrangement responds to mechanical signals (Hamant et al., 2008), which are likely to be transmitted between layers. Therefore, it is possible that the formation of domed cells in the star epidermis is merely triggered by mechanical signals from the growing underlying layer, independent of any petal identity specifier. The molecular or physical nature of the signals involved in communication between layers deserves to be explored in full depth.

\section{Towards the gene regulatory networks of petal development}

Our star and wico material granted the opportunity to explore the gene regulatory networks driving petal development in petunia, more specifically by decoupling tube vs. limb development on one hand, and epidermis vs. mesophyll development on the other hand. However, these effects are confounded in our dataset, since mesophyll and tube development are linked in star flowers, whereas epidermis and limb development are linked in wico flowers. Further analyses, like for instance sequencing the transcriptome from star and wico limb and tube tissues separately, would help uncouple these effects. Anyhow, to evaluate the potentiality of our transcriptomic dataset to yield functional results, we focused our analysis on anthocyanin-related genes since we expected them to be downregulated in the white petals of star flowers, and because the anthocyanin biosynthesis and regulatory pathways are very well characterized. Therefore, we examined the presence of anthocyanin-related genes among genes downregulated both in star and phdef-151 samples, but not deregulated in wico samples. We found a very high number of anthocyanin-related genes in this dataset, suggesting that the initial triggering event for most of the anthocyanin production pathway was missing in star flowers. Most of these genes were downregulated in star samples from stage 8 onwards, which is consistent with the late appearance of pigmentation in the limbs of wild-type petals.

Finally, we investigated the direct link between PhDEF and petal pigmentation and found that, in vitro, the PhDEF $+\mathrm{PhGLO} 1$ protein complex directly binds to a good predicted binding site in the regulatory region of $A N 1$. Specifically, this site lies in the terminator region of $A N 1$, which is not incompatible with an activating role in transcription, through DNA looping to the promoter (Jash et al., 2012) or by promoting transcription termination and reinitiation (Wang et al., 2000). Therefore, we hypothesize that PhDEF directly activates AN1 expression, thereby triggering the petal pigmentation program. Indeed petunia an 1 mutants have completely white petals, consistent with the most upstream position of AN1 in the anthocyanin regulatory pathway (Doodeman et al., 1984; Spelt et al., 2000). If confirmed, the fact that PhDEF regulates the expression of pigmentation 
bioRxiv preprint doi: https://doi.org/10.1101/2021.04.03.438311; this version posted April 4, 2021. The copyright holder for this preprint (which was not certified by peer review) is the author/funder, who has granted bioRxiv a license to display the preprint in perpetuity. It is made available under aCC-BY-NC-ND 4.0 International license.

genes would contribute to fill the « missing link » between the identity of a floral organ and its final appearance (Dornelas et al., 2011). 


\section{MATERIALS AND METHODS}

\section{Plant material, growth conditions and plant phenotyping}

The phdef-151 plants were obtained from the Petunia $x$ hybrida W138 line and were grown in a culture room in long day conditions $\left(16 \mathrm{~h}\right.$ light $22^{\circ} \mathrm{C} ; 8 \mathrm{~h}$ night $18^{\circ} \mathrm{C} ; 75$-WValoya NS12 LED bars; light intensity: $130 \mu \mathrm{E}$ ). The wico and star flowers were repeatedly obtained from several different phdef-151 individuals and were maintained by cuttings. Plant and flower pictures were obtained with a CANON EOS 450D camera equipped with objectives SIGMA 18-50mm or SIGMA 50mm. To measure tube length, the flower was cut longitudinally and photographed from the side. To measure limb area, the limbs were flattened as much as possible on a glass slide covered with transparent tape and photographed from the top. The photographs were used to measure D1 and D2 lengths and limb area with ImageJ.

\section{Genotyping}

Extraction of genomic DNA from young leaf tissue was performed according to Edwards et al., 1991. The region spanning the $d T p h 1$ insertion site in $P h D E F$ was amplified using primers MLY0935/MLY0936 (Table S1). PCR products were separated on a 2\% agarose gel, fragments of interest were purified using the NucleoSpin ${ }^{\circledR}$ Gel and PCR Clean-up kit (Macherey-Nagel), and sequenced with Eurofins SupremeRun reactions.

\section{In situ RNA Hybridization}

Floral buds from wild-type, 2 wico and 1 star lines were fixated overnight in FAA (3.7\% formaldehyde, 5\% acetic acid, 50\% ethanol), cleared in Histo-clear and embedded in paraffin to perform $8 \mu \mathrm{m}$ sections. PhDEF cDNA was amplified from wild-type petunia inflorescence cDNAs with primers MLY1738/MLY1739 (Table S1), generating a 507 bp fragment excluding the part encoding the highly conserved DNA-binding domain. The digoxigenin-labeled RNA probe was synthesized from the PCR fragment by in vitro transcription, using T7 RNA polymerase (Boehringer Mannheim). RNA transcripts were hydrolyzed partially for $42 \mathrm{~min}$ by incubation at $60^{\circ} \mathrm{C}$ in $0.1 \mathrm{M} \mathrm{Na}_{2} \mathrm{CO}_{3} / \mathrm{NaHCO}_{3}$ buffer, $\mathrm{pH}$ 10.2. Later steps were performed as described by (Cañas et al., 1994). For imaging, slides were mounted in Entellan (Sigma) and imaged with a Zeiss Axio Imager M2 light microscope equipped with a Zeiss Axio Cam HRc camera.

\section{Scanning Electron Microscopy (SEM)}

Scanning electron micrographs were obtained with a HIROX SH-1500 bench top environmental scanning electron miscroscope equipped with a cooling stage. Samples were collected and quickly 
imaged to limit dehydration, at $-5^{\circ} \mathrm{C}$ and $5 \mathrm{kV}$ settings. For cell area and length measurements, pictures were taken from 3 petal tubes and 3 petal limbs from different wild-type, star and wico flowers. For each sample, 3 pictures were taken and 5 cells (for the tube) or 10 cells (for the limbs) were measured for each picture. Measures were performed with ImageJ by manually drawing the outline or length of the cells.

\section{RNA-Seq}

Petal tissue was collected at $1 \mathrm{pm}$ from several plants steming from a single star line, a single wico line, and several individual wild-type plants (progeny of a single star flower) and phdef-151 plants (progeny of the same star flower). Tube length was macroscopically measured to compare stages, the corolla was cut open and stamens were removed as much as possible from the corolla by pulling on the filaments fused to the tube. One biological replicate contains total petal tissue from 2 flowers. Tissue was grounded in liquid nitrogen and RNA was extracted with the Spectrum Plant Total RNA Kit (Sigma) including on-column DNase digestion (Sigma). RNA integrity and quantity were determined by a Bioanalyzer RNA 6000 Nano assay (Agilent). Libraries were prepared with poly-A enrichment and single-end 75-bp sequencing was performed on a NextSeq 500 platform (Illumina). 16 to 23 million reads were recovered per library. Reads were checked for quality with FastQC v0.11.4 (https://www.bioinformatics.babraham.ac.uk/projects/fastqc/), adaptors and lowquality ends were trimmed with Cutadapt v 1.16 (Martin, 2011) and custom Perl scripts. The reference genome sequence used for transcriptome analysis is the Petunia axillaris v1.6.2 HiC genome published in (Bombarely et al., 2016) and further scaffolded by HiC by DNAzoo (Dudchenko et al., 2017, 2018); gene annotations were transferred from the published assembly to the HiC-scaffolded version using Blat (Kent, 2002), Exonerate (Slater and Birney, 2005) and custom Perl scripts. The complete set of reads was mapped on the reference genome sequence using HISAT2 v2.2.1 (Kim et al., 2015) to identify splicing sites, before performing mapping sample per sample. Reads per gene were counted using FeatureCounts v1.5.1 (Liao et al., 2014). DESeq2 version 3.12 (Love et al., 2014) was used with $\mathrm{R}$ version 4.0.3 to perform the Principal Component Analysis and the differential gene expression analysis. Genes having less than 10 reads in the sum of all samples were considered as non-expressed and discarded. Genes were considered to be deregulated if $\log 2$ FoldChange $>1$ or $<-1$, and p-adjusted value $<0.01$. Venn diagrams were built with InteractiVenn (Heberle et al., 2015).

\section{Prediction of MADS-box TF binding sites}

Genomic sequences, starting $3 \mathrm{~kb}$ upstream the START codon and ending $1 \mathrm{~kb}$ downstream the STOP codon, from $P h D E F, A N 1$ and $A N 2$ were scanned with all MADS-box TF matrices included 
in the Jaspar 2020 database (http://jaspar.genereg.net), only removing matrices from AGL42 and AGL55 which are much shorter than the other matrices and therefore yield much higher scores. Relative scores above 0.86 were plotted against their genomic position.

\section{Electrophoretic Gel Shift Assays (EMSAs)}

CDS sequences from PhDEF and PhGLO1 were amplified from Petunia $x$ hybrida R27 inflorescence cDNAs with primers MLY2382/MLY2383 and MLY2384/2385 respectively (Table $\mathrm{S} 1$ ) and cloned into the in vitro translation vector pSPUTK (Stratagene) by NcoI/XbaI restriction. From these vectors, the PhDEF and PhGLO1 proteins were produced with the TnT SP6 High-Yield Wheat Germ Protein Expression System (Promega) according to the manufacturer's instructions. The genomic sequence from AN1 terminator $(0.8 \mathrm{~kb})$ was amplified from Petunia $x$ hybrida $\mathrm{R} 27$ genomic DNA with primers from Table S1 and cloned into pCR-BluntII-TOPO (ThermoFisher). Binding sites were amplified from these plasmids with primers listed in Table S1, with the forward primer labelled with Cy5 in 5'. The labelled DNA was purified and incubated with the TnT in vitro translation mixture as described in (Silva et al., 2015) before loading on a native acrylamide gel. 

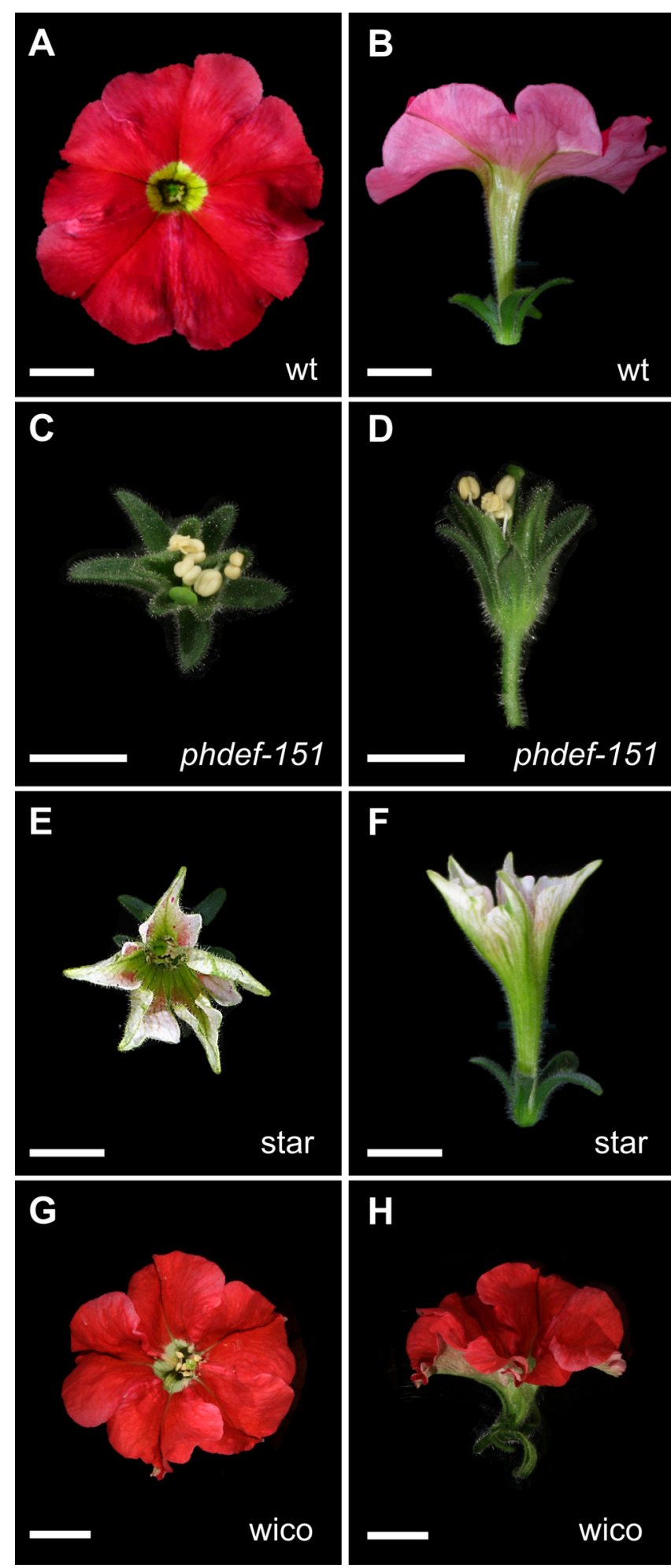
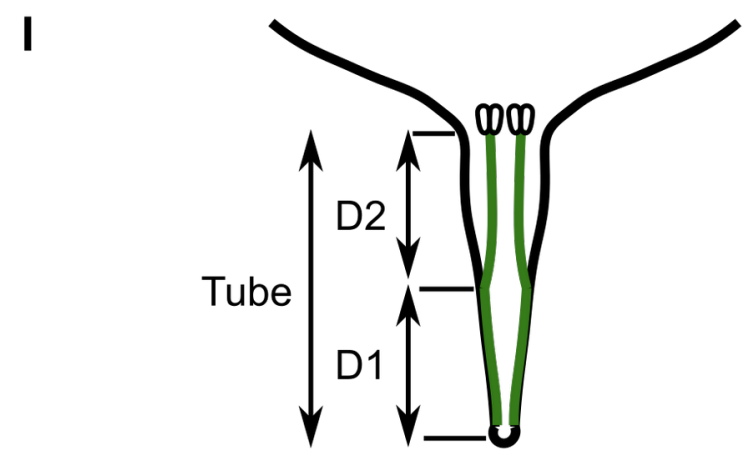

$\mathbf{J}$

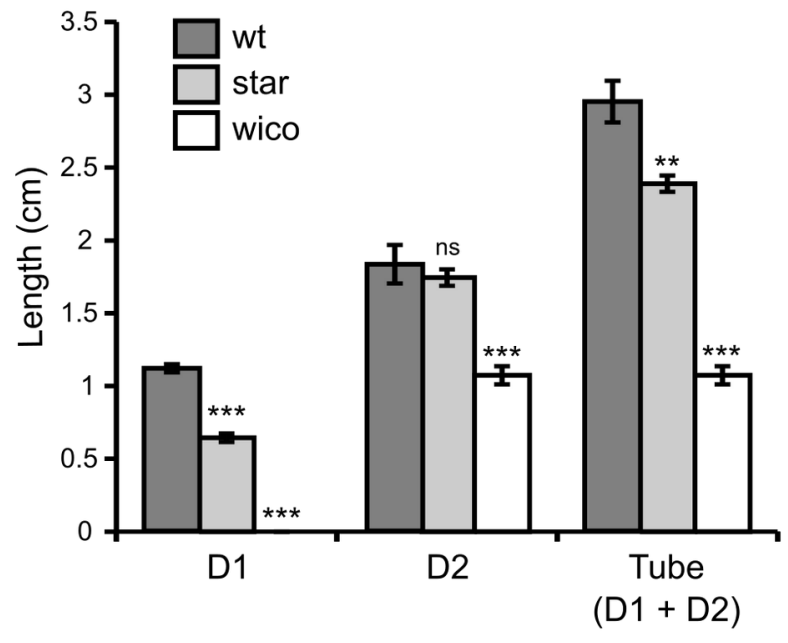

K

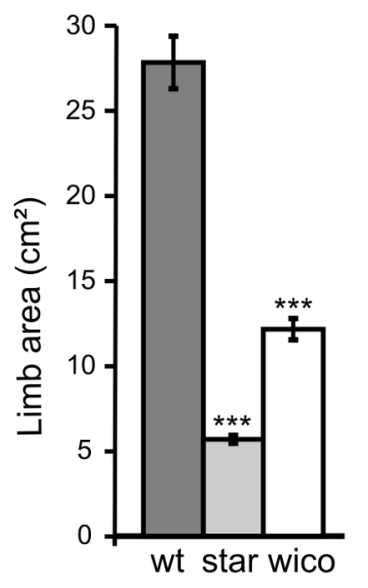

$\mathbf{L}$

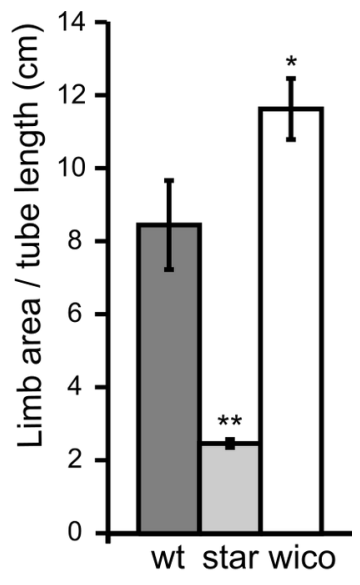

Figure 1. Macroscopic description of the star and wico flowers.

(A-J) Wild type (A, B), phdef-151 (C, D), star (E, F) and wico wico (G, H) flowers from a top and side view respectively. Scale bar: $1 \mathrm{~cm}$. (I) Schematic cross-section of a wild type flower, showing stamens (in green) partially fused to the petal tube. The region of the tube fused to stamens is named D1, and the region of the tube where stamens are free is named D2, as defined in (Stuurman 
et al., 2004). (J) Average length of regions D1, D2 and total tube length in wt, star and wico flowers. (K) Average limb area in wt, star and wico flowers. (L) Average ratio between limb area and tube length in wt, star and wico flowers. $\mathrm{n}=7 \mathrm{wt}$ flowers, $\mathrm{n}=12$ star flowers from 4 different branches, $\mathrm{n}=18$ wico flowers from 5 different branches. Student's t test $(* \mathrm{p}<0.05, * * \mathrm{p}<0.01$, $* * * \mathrm{p}<0.005)$. Error bars represent \pm s.e.m. 


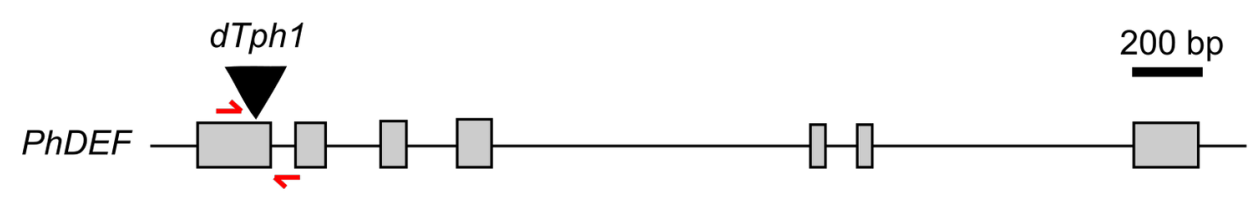

B

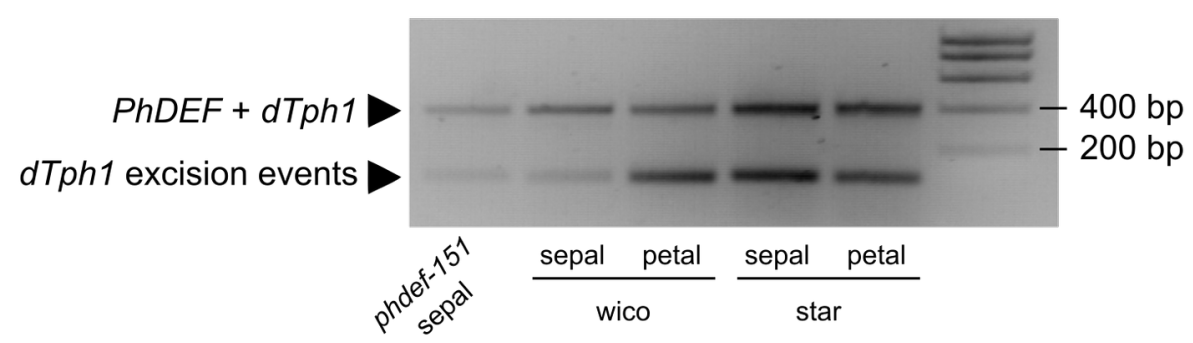

C

\begin{tabular}{|c|c|c|c|}
\hline Phenotype & Allele & Nucleotidic sequence & Protein Sequence \\
\hline wt & PhDEF & CCAGTA------CTGG--------CAAGCTTCAT & DAKVSIIMISS--TG--KLHEFIS \\
\hline phdef & $\begin{array}{l}\text { phdef }(+8) \\
\text { phdef }(+7)\end{array}$ & $\begin{array}{l}\text { CCAGTA------CTGGCAGTCTGGCAAGCTTCAT } \\
\text { CCAGTA------CTGGC-GTCTGGCAAGCTTCAT }\end{array}$ & $\begin{array}{l}\text { DAKVSIIMISS--TGSLASFMNSI (+22aa) * } \\
\text { DAKVSIIMISS--TGVWQAS* }\end{array}$ \\
\hline star & $\begin{array}{l}\text { PhDEF } \\
\text { phdef }(+6 a) \\
\text { phdef }(+6 b)\end{array}$ & $\begin{array}{l}\text { CCAGTA------CTGG-------CAAGCTTCAT } \\
\text { CCAGTA------CTGG--GTCTGGCAAGCTTCAT } \\
\text { CCAGTA------CTGGCA-T-TGGCAAGCTTCAT }\end{array}$ & $\begin{array}{l}\text { DAKVSIIMISS--TG--KLHEFIS } \\
\text { DAKVSIIMISS--TGSGKLHEFIS } \\
\text { DAKVSIIMISS--TGIGKLHEFIS }\end{array}$ \\
\hline wico & $\begin{array}{ll}\text { PhDEF } & \\
\text { phdef } & (+6 a) \\
\text { phdef } & (+6 c) \\
\text { phdef } & (+6 d)\end{array}$ & $\begin{array}{l}\text { CCAGTA-----CTGG------CAAGCTTCAT } \\
\text { CCAGTA-----CTGG--GTCTGGCAAGCTTCAT } \\
\text { CCAGTA------CTGGCA--CTGGCAAGCTTCAT } \\
\text { CCAGTAGCCAGTCTGG-------CAAGCTTCAT }\end{array}$ & $\begin{array}{l}\text { DAKVSIIMISS--TG--KLHEFIS } \\
\text { DAKVSIIMISS--TGSGKLHEFIS } \\
\text { DAKVSIIMISS--TGTGKLHEFIS } \\
\text { DAKVSIIMISSSQSG--KLHEFIS }\end{array}$ \\
\hline
\end{tabular}

Figure 2. Sequencing the PhDEF excision alleles in star and wico flowers.

(A) $P h D E F$ gene model indicating the position of the $d T p h 1$ insertion in the first exon (black triangle) and the primers used for subsequent amplification and sequencing (in red). (B) Amplicons generated with primers spanning the $d T p h 1$ insertion site, on genomic DNA from phdef-151 second whorl organs and star and wico sepals and petals. The large fragment still contains the $d T p h 1$ transposon inserted (expected size: $407 \mathrm{bp}$ ), while small fragments result from different events of dTph1 excision (expected size: $115 \mathrm{bp}$ ) and were subsequently sequenced. (C) The small PhDEF fragments from (B) were sequenced in the second whorl organs of flowers with a phdef $(\mathrm{n}=2)$, star $(n=14)$ and wico $(n=14)$ phenotype. The nucleotidic sequence and predicted protein sequence are indicated, with STOP codons represented by a star. Additional nucleotides or amino-acids as compared to the wild-type sequences are indicated in red. $n=$ number of independent reversion events where the same excision footprint was found. 

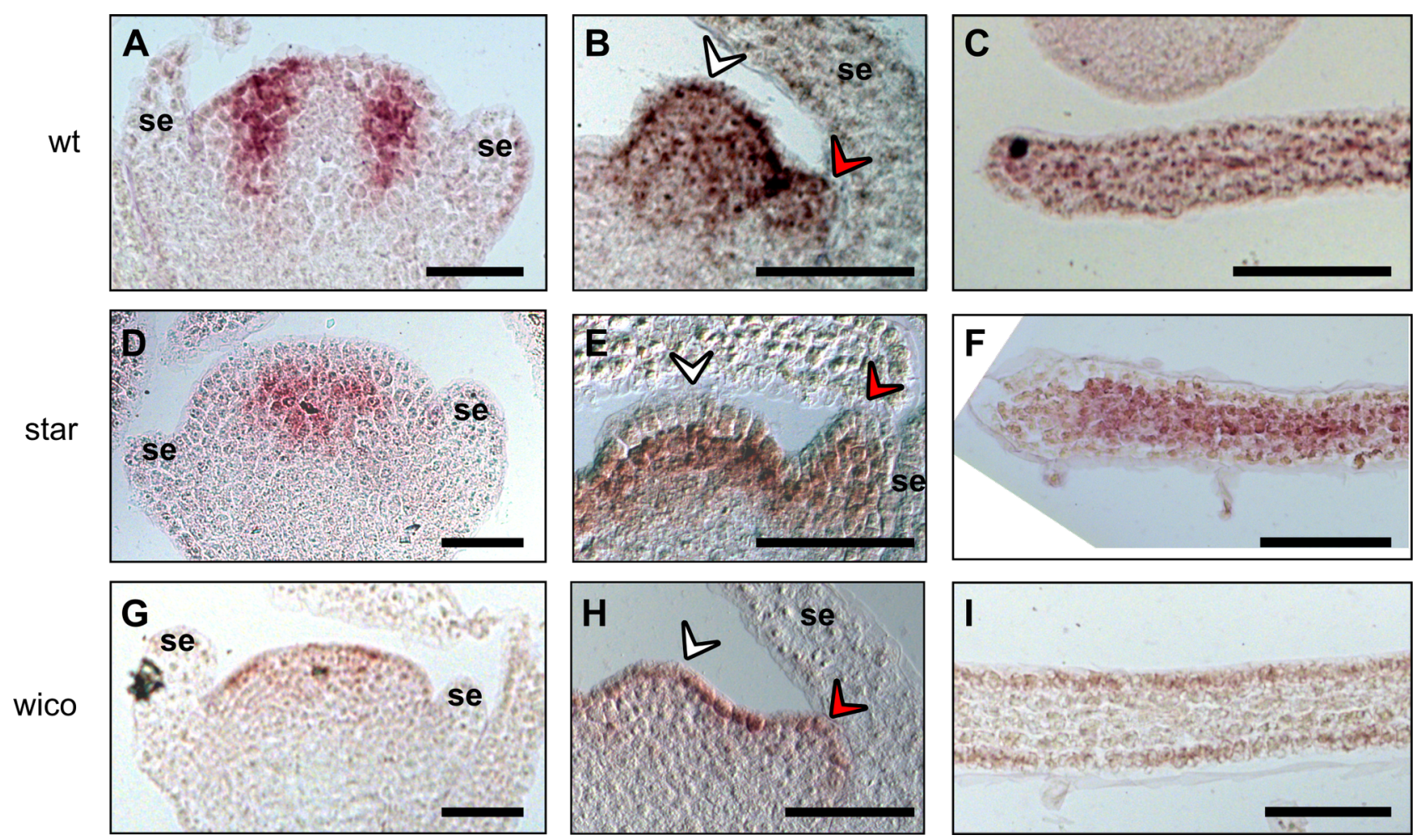

Figure 3. Localization of the PhDEF transcript in wild-type, star and wico flowers by in situ hybridization.

Longitudinal sections of wild-type (A, B, C), star (D, E, F) and wico (G, H, I) flowers or young petals hybridized with a DIG-labelled $P h D E F$ antisense probe. At the earliest stage chosen (A, D, G), sepals are initiating and $P h D E F$ is expressed in the future petal / stamen initiation domain. Note that if the section was not performed at the center of the flower, the $P h D E F$ signal might artificially appear to be in the middle of the flower (as in D) whereas it is actually on its flanks. At the middle stage chosen (B, E, H), stamens (white arrowhead) and petals (red arrowhead) are initiating, and $P h D E F$ is expressed in both primordia. $P h D E F$ expression is also detected at the tip of young petal limbs (C, F, I). se: sepals. Scale bar: $50 \mu \mathrm{m}$. 

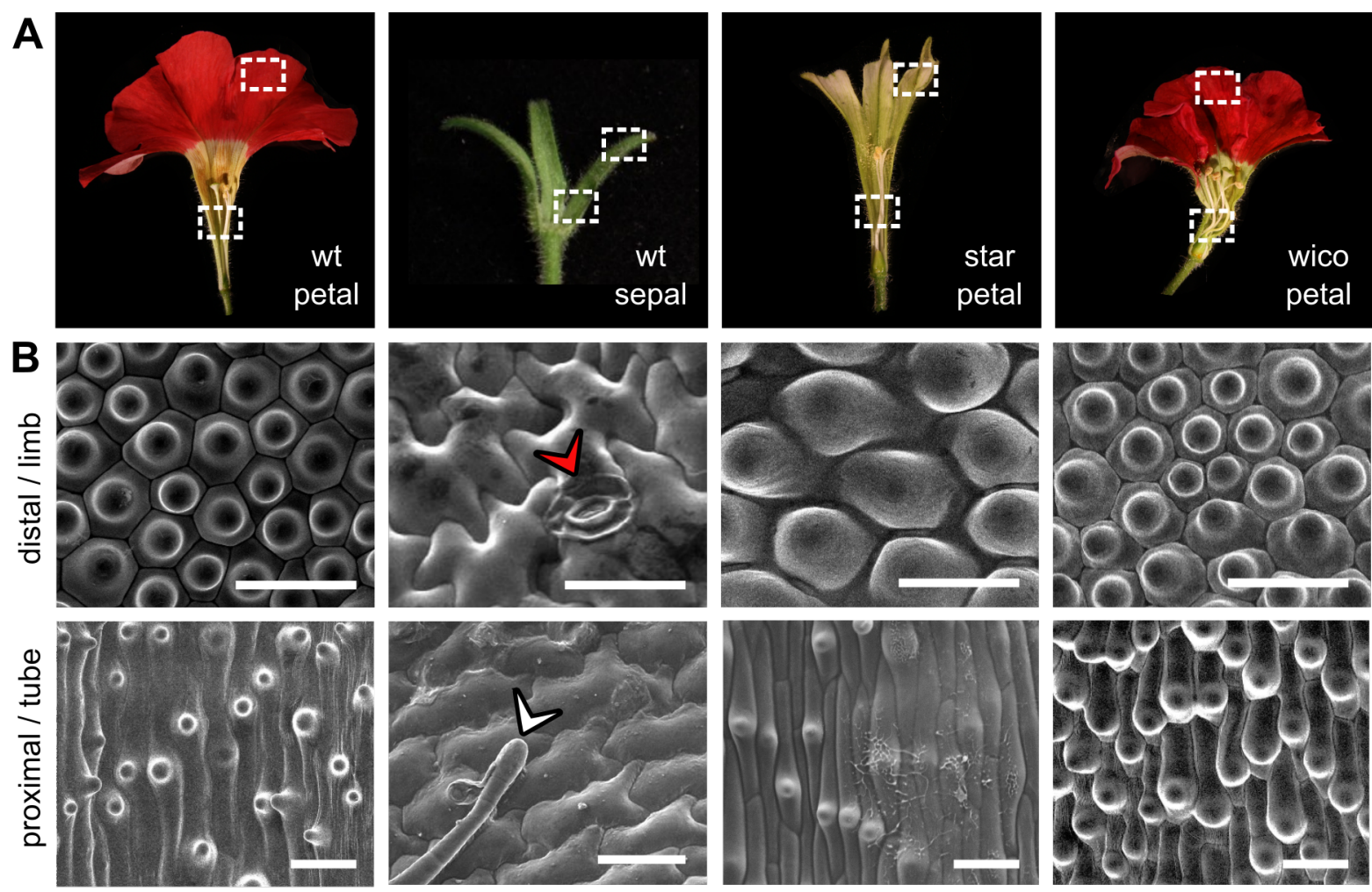

C

D

E
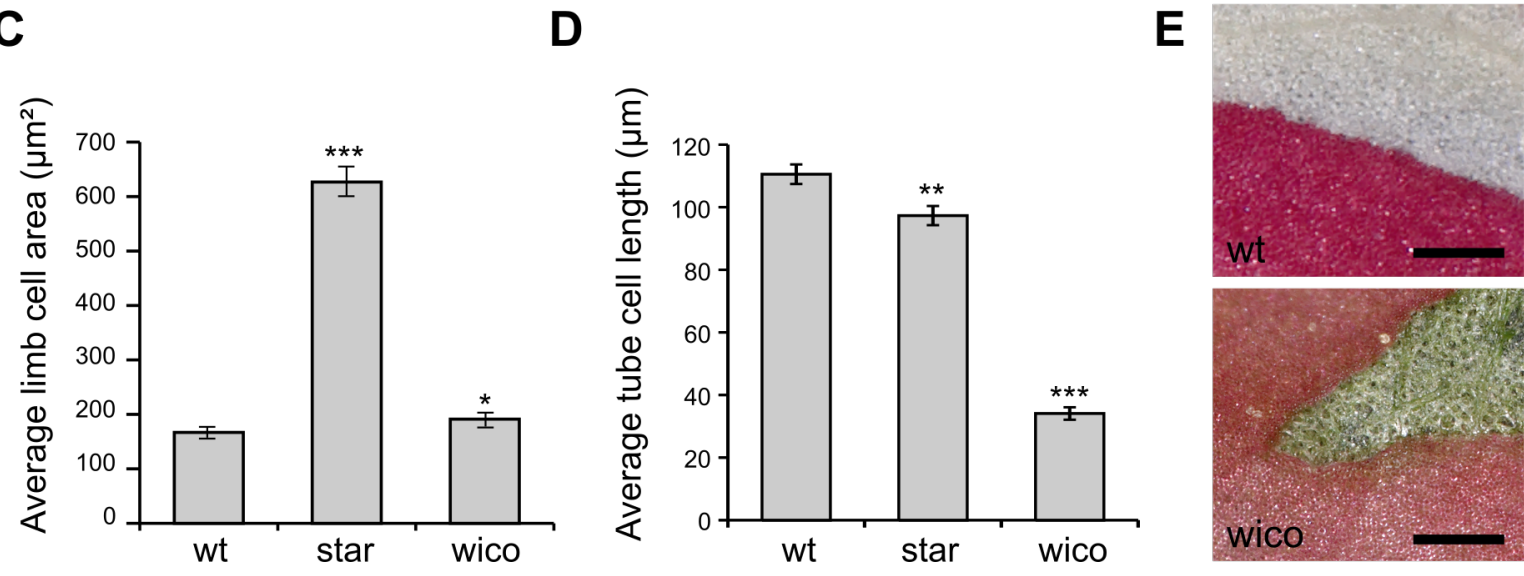

Figure 4. Epidermal cell identities in wt petals and sepals, and star and wico petals.

(A) From left to right: wt petals, wt sepals, star petals and wico petals cut open longitudinally to show areas used for scanning electron microscopy and cross-sections. Petals were subdivided into limb and tube area, and sepals were subdivided into a distal and a proximal part, as shown by the dotted white rectangles. (B) Representative scanning electron micrographs from the adaxial side of a wt petal, wt sepal, star petal and wico petal (from left to right). The red arrow points to a stomata and the white arrow points to a trichome. Scale bar: $30 \mu \mathrm{m}$. (C) Average limb cell area from the adaxial side of wild-type, star and wico petals $(n=30$ cells $)$. Student's $t$ test $(* p<0.05, * * p<0.01$, $* * * \mathrm{p}<0.005)$. (D) Average tube cell length from the adaxial side of wild-type, star and wico petals ( $\mathrm{n}=45$ cells). Wilcoxon rank sum test $(* \mathrm{p}<0.05, * * \mathrm{p}<0.01, * * * \mathrm{p}<0.005)$. Error bars represent \pm s.e.m. (E) Limb area from wild-type (top) and wico (bottom) petals, after their adaxial epidermis 
bioRxiv preprint doi: https://doi.org/10.1101/2021.04.03.438311; this version posted April 4, 2021. The copyright holder for this preprint (which was not certified by peer review) is the author/funder, who has granted bioRxiv a license to display the preprint in perpetuity. It is made available under aCC-BY-NC-ND 4.0 International license.

was manually peeled. For wt, the upper half of the picture shows the white underlying mesophyll.

For wico, the green triangular area shows the green (chloroplastic) underlying mesophyll. 

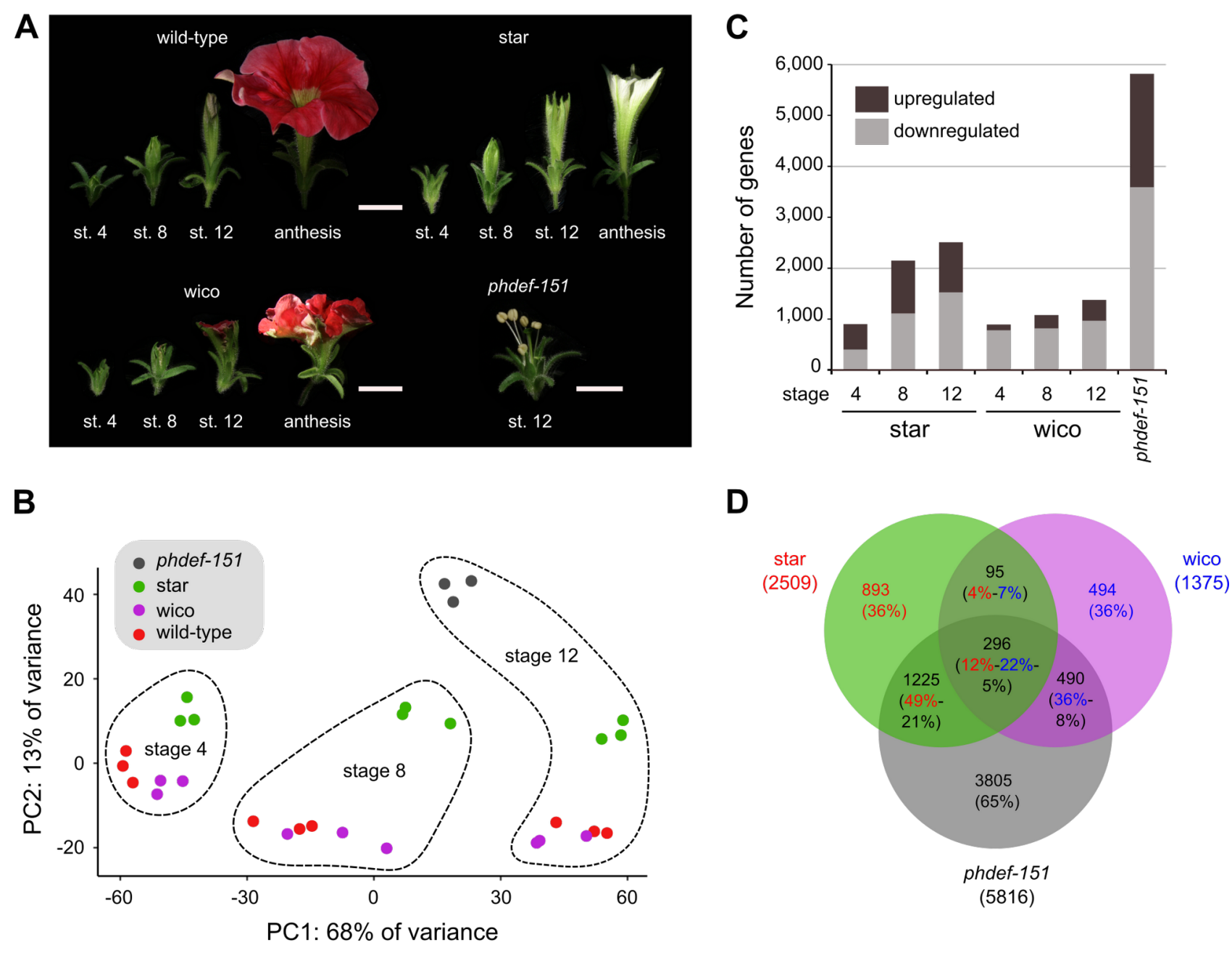

Figure 5. Gene deregulation in star and wico petals.

(A) Flowers from wild-type, star, wico and phdef-151 at stages 4, 8 and 12 (only stage 12 for phdef151), whose petals or sepals were harvested for transcriptome sequencing. Flowers at anthesis are shown for comparison. Scale bar: $1 \mathrm{~cm}$. (B) Principal Component Analysis plot of the samples after analysis of variance with DESeq2, showing that the first principal component corresponds to the developmental stage and the second principal component corresponds to the genotype. (C) Number of upregulated and downregulated genes in star, wico and phdef-151, as compared to wild-type at the corresponding stages. (D) Venn diagram recapitulating the number of deregulated genes in star, wico and phdef-151 petal samples at stage 12, as compared to wild-type, and their different intersections. Each sector contains the number of deregulated genes, and between parenthesis is the percentage of genes that it represents from the total number of deregulated genes in the corresponding sample, with a colour code (red = percentage of deregulated genes from star samples $/$ blue $=$ from wico samples $/$ black $=$ from phdef-151 samples). 


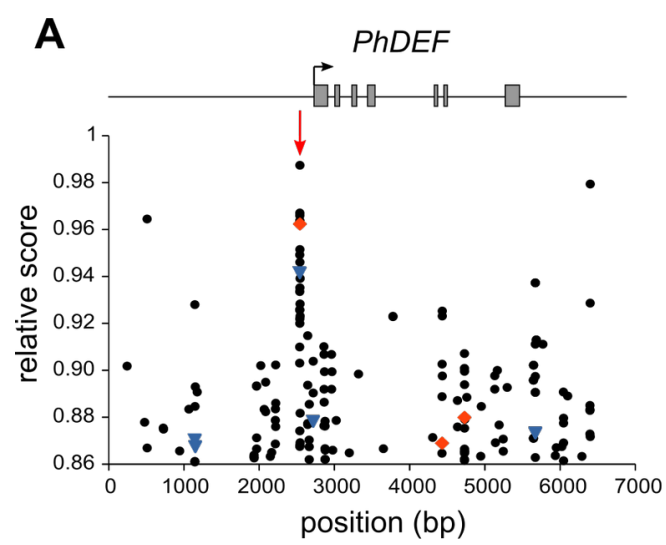

C

\begin{tabular}{ccccc}
\hline PhDEF & - & + & - & + \\
\hline PhGLO1 & - & - & + & + \\
\hline AN1-bs1 & + & + & + & + \\
& & & & \\
& & & & \\
& & & & \\
& & & &
\end{tabular}

B

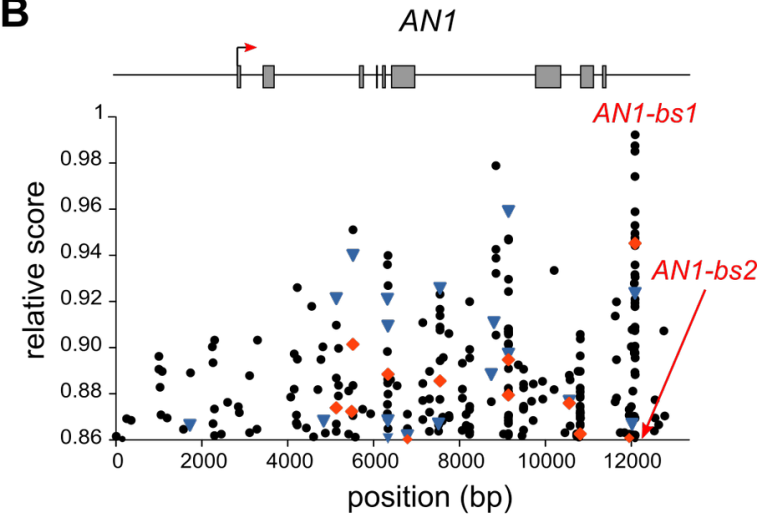

Figure 6. PhDEF with its PhGLO1 partner directly binds in vitro to the $A N 1$ terminator region. (A, B) Relative score profiles for AP3 (red diamond), PI (blue triangle) and all other MADS-box TFs (black dot) available on Jaspar, on the genomic sequences of PhDEF (A) and AN1 (B). The relative score is computed using the position weight matrix of each $\mathrm{TF}$ and is between 0 and 1; only relative scores higher than 0.86 are shown here. The gene model is represented above the score profile with exons as grey rectangles, and the transcription start site as an arrow. For $P h D E F$, the position of a high-confidence CArG box, as explained in the main text, is indicated by a red arrow. For $A N 1$, the positions of $A N 1-b s 1$ (putative PhDEF binding site) and $A N 1-b s 2$ (negative control with a low predicted binding score) are indicated in red. (C) Electrophoretic mobility shift assays (EMSAs) performed with a combination of in vitro-translated PhDEF and/or PhGLO1 proteins, and Cy5-labelled $A N 1-b s 1$ or $A N 1-b s 2$ DNA fragments. Slight differences in DNA quantities explain differences in shift intensities for $A N 1-b s 1$ between the two gels. 


\begin{tabular}{|c|c|c|c|c|}
\hline & & \multicolumn{3}{|c|}{ Phenotype of the progeny (\% of the total) } \\
\hline & & phdef & wild-type & pink wild-type \\
\hline \multirow{11}{*}{ Parent flower } & wico-1 & $15(94 \%)$ & & $1(6 \%)$ \\
\hline & wico-2 & $14(88 \%)$ & $1(6 \%)$ & $1(6 \%)$ \\
\hline & wico-3 & $16(100 \%)$ & & \\
\hline & wico-4 & $15(94 \%)$ & & $1(6 \%)$ \\
\hline & wico-5 & $16(100 \%)$ & & \\
\hline & wico-6 & $12(100 \%)$ & & \\
\hline & wico-7 & $12(100 \%)$ & & \\
\hline & star-1 & $11(46 \%)$ & $4(17 \%)$ & $9(38 \%)$ \\
\hline & star-2 & $4(25 \%)$ & $4(25 \%)$ & $8(50 \%)$ \\
\hline & star-3 & $7(29 \%)$ & $5(21 \%)$ & $12(50 \%)$ \\
\hline & star-4 & $3(19 \%)$ & $3(19 \%)$ & $10(63 \%)$ \\
\hline
\end{tabular}

Table 1. Progeny of the star and wico flowers after selfing.

7 wico flowers and 4 star flowers have been selfed and their progeny has been phenotyped and classified into phdef, wild-type or pink wild-type phenotype. Summing the star progeny for the 4 parents gives 25 phdef, 16 wild-type and 39 pink wild-type plants, which is not significantly different to a $1: 1: 2$ ratio (chi-square test, $p=0.22$ ). Note that for wico, we found 4 plants with wildtype or pink wild-type flowers in the progeny, and all of them were linked to the presence of a de novo transposon excision from the $P h D E F$ locus, restoring either a $P h D E F+6$ (in the case of pink wild-type progeny) or a wild-type $P h D E F$ (in the case of the wild-type progeny) allele. 


\section{Acknowledgments}

We thank Patrice Bolland, Justin Berger and Alexis Lacroix for plant care assistance, the PLATIM platform (SFR BioSciences Lyon, UAR3444/CNRS, US8/Inserm, ENS de Lyon, UCBL) for electron microscopy technical support, Benjamin Gillet and Sandrine Hugues from the sequencing platform of the Institut de Génomique Fonctionnelle de Lyon for library preparation and sequencing of the transcriptomes of this study, and Rémy Belois for assistance for in situ hybridization experiments. This work was supported by grants to M.M. from the Agence Nationale de la Recherche (grant ANR-19-CE13-0019, FLOWER LAYER) and from IDEXLYON (Université de Lyon, grant ELAN-ERC), by a PhD fellowship to M.C. from the French Ministry of Higher Education and Research, and by a grant to V.H. and C.Z. from the Agence Nationale de la Recherche (grant ANR-16-CE92-0023, FLOPINET).

\section{Author Contribution}

M.M. and M.V conceived and designed the experiments. M.C., Q.C.S, P.M., P.C., V.H. and S.R.B. performed the experiments. M.C., Q.C.S., J.J., M.V. and M.M. analyzed the data. M.C., C.Z., M.V. and M.M. wrote the article.

\section{Supporting Information}

Figure S1. Additional pictures of star and wico flowers.

Figure S2. Stamens are unfused to the tube in wico flowers.

Figure S3. Wild-type and pink wild-type flowers descendant from a star parent.

Figure S4. Additional pictures of PhDEF transcript in situ hybridization in wild-type, star and wico flowers.

Figure S5. Epidermal revertant sectors on star petals.

Figure S6. Autonomous and non-autonomous effects in star and wico petals.

Figure S7. Prediction of MADS-box DNA binding sites in the genomic sequence of AN2.

Table S1. List of primers used in this study.

Table S2. Genotyping results of the progeny of a star flower.

Table S3. Differential gene expression calculated by DESeq2.

Table S4. List of the 504 genes downregulated in star and phdef-151 samples. 


\section{References}

Albert, N.W., Lewis, D.H., Zhang, H., Schwinn, K.E., Jameson, P.E., and Davies, K.M. (2011). Members of an R2R3-MYB transcription factor family in Petunia are developmentally and environmentally regulated to control complex floral and vegetative pigmentation patterning. Plant $\mathrm{J}$ 65: 771-784.

Angenent, G.C., Busscher, M., Franken, J., Mol, J.N., and van Tunen, A.J. (1992). Differential expression of two MADS box genes in wild-type and mutant petunia flowers. Plant Cell 4: 983993.

Bissell, E.K. and Diggle, P.K. (2008). Floral Morphology in Nicotiana: Architectural and Temporal Effects on Phenotypic Integration. International Journal of Plant Sciences 169: 225-240.

Bombarely, A. et al. (2016). Insight into the evolution of the Solanaceae from the parental genomes of Petunia hybrida. Nat Plants 2: 16074.

Bouhidel, K. and Irish, V.F. (1996). Cellular Interactions Mediated by the

HomeoticPISTILLATAGene Determine Cell Fate in theArabidopsisFlower. Developmental Biology 174: 22-31.

Brandoli, C., Petri, C., Egea-Cortines, M., and Weiss, J. (2020). The clock gene Gigantea 1 from Petunia hybrida coordinates vegetative growth and inflorescence architecture. Sci Rep 10: 275.

Cañas, L.A., Busscher, M., Angenent, G.C., Beltrán, J.-P., and Tunen, A.J.V. (1994). Nuclear localization of the petunia MADS box protein FBP1. The Plant Journal 6: 597-604.

Cartolano, M., Castillo, R., Efremova, N., Kuckenberg, M., Zethof, J., Gerats, T., SchwarzSommer, Z., and Vandenbussche, M. (2007). A conserved microRNA module exerts homeotic control over Petunia hybrida and Antirrhinum majus floral organ identity. Nat Genet 39: 901-905. Coen, E.S. and Meyerowitz, E.M. (1991). The war of the whorls: genetic interactions controlling flower development. Nature 353: 31-37.

De Keukeleire, P., Maes, T., Sauer, M., Zethof, J., Van Montagu, M., and Gerats, T. (2001). Analysis by Transposon Display of the behavior of the dTph1 element family during ontogeny and inbreeding of Petunia hybrida. Mol Genet Genomics 265: 72-81.

Doodeman, M., Boersma, E.A., Koomen, W., and Bianchi, F. (1984). Genetic analysis of instability in Petunia hybrida : 1. A highly unstable mutation induced by a transposable element inserted at the An1 locus for flower colour. Theor Appl Genet 67: 345-355.

Dornelas, M.C., Patreze, C.M., Angenent, G.C., and Immink, R.G.H. (2011). MADS: the missing link between identity and growth? Trends Plant Sci 16: 89-97.

Dudchenko, O. et al. (2018). The Juicebox Assembly Tools module facilitates de novo assembly of mammalian genomes with chromosome-length scaffolds for under \$1000. bioRxiv: 254797.

Dudchenko, O., Batra, S.S., Omer, A.D., Nyquist, S.K., Hoeger, M., Durand, N.C., Shamim, M.S., Machol, I., Lander, E.S., Aiden, A.P., and Aiden, E.L. (2017). De novo assembly of the Aedes aegypti genome using Hi-C yields chromosome-length scaffolds. Science 356: 92-95. Efremova, N., Perbal, M.-C., Yephremov, A., Hofmann, W.A., Saedler, H., and SchwarzSommer, Z. (2001). Epidermal control of floral organ identity by class B homeotic genes in Antirrhinum and Arabidopsis. Development 128: 2661-2671.

Fornes, O. et al. (2020). JASPAR 2020: update of the open-access database of transcription factor binding profiles. Nucleic Acids Res 48: D87-D92.

Frank, M.H. and Chitwood, D.H. (2016). Plant chimeras: The good, the bad, and the "Bizzaria." Dev. Biol. 419: 41-53.

Galliot, C., Stuurman, J., and Kuhlemeier, C. (2006). The genetic dissection of floral pollination syndromes. Curr Opin Plant Biol 9: 78-82.

Gerats, A.G., Huits, H., Vrijlandt, E., Marana, C., Souer, E., and Beld, M. (1990). Molecular characterization of a nonautonomous transposable element (dTph1) of petunia. Plant Cell 2: 11211128. 
Hamant, O., Heisler, M.G., Jönsson, H., Krupinski, P., Uyttewaal, M., Bokov, P., Corson, F., Sahlin, P., Boudaoud, A., Meyerowitz, E.M., Couder, Y., and Traas, J. (2008). Developmental patterning by mechanical signals in Arabidopsis. Science 322: 1650-1655.

Heberle, H., Meirelles, G.V., da Silva, F.R., Telles, G.P., and Minghim, R. (2015). InteractiVenn: a web-based tool for the analysis of sets through Venn diagrams. BMC Bioinformatics 16: 169.

Heijmans, K., Ament, K., Rijpkema, A.S., Zethof, J., Wolters-Arts, M., Gerats, T., and Vandenbussche, M. (2012). Redefining C and D in the petunia ABC. Plant Cell 24: 2305-2317. Hill, T.A., Day, C.D., Zondlo, S.C., Thackeray, A.G., and Irish, V.F. (1998). Discrete spatial and temporal cis-acting elements regulate transcription of the Arabidopsis floral homeotic gene APETALA3. Development 125: 1711-1721.

Hoballah, M.E., Gubitz, T., Stuurman, J., Broger, L., Barone, M., Mandel, T., Dell'Olivo, A., Arnold, M., and Kuhlemeier, C. (2007). Single gene-mediated shift in pollinator attraction in Petunia. Plant Cell 19: 779-790.

van Houwelingen, A., Souer, E., Mol, J., and Koes, R. (1999). Epigenetic interactions among three dTph1 transposons in two homologous chromosomes activate a new excision-repair mechanism in petunia. Plant Cell 11: 1319-1336.

Jash, A., Yun, K., Sahoo, A., So, J.-S., and Im, S.-H. (2012). Looping mediated interaction between the promoter and 3' UTR regulates type II collagen expression in chondrocytes. PLoS One 7: e40828.

Jenik, P.D. and Irish, V.F. (2000). Regulation of cell proliferation patterns by homeotic genes during Arabidopsis floral development. Development 127: 1267-1276.

Jenik, P.D. and Irish, V.F. (2001). The Arabidopsis floral homeotic gene APETALA3 differentially regulates intercellular signaling required for petal and stamen development. Development 128: 1323.

Kent, W.J. (2002). BLAT-The BLAST-Like Alignment Tool. Genome Res. 12: 656-664. Kim, D., Langmead, B., and Salzberg, S.L. (2015). HISAT: a fast spliced aligner with low memory requirements. Nat Methods 12: 357-360.

Koes, R., Verweij, W., and Quattrocchio, F. (2005). Flavonoids: a colorful model for the regulation and evolution of biochemical pathways. Trends Plant Sci 10: 236-242.

Kostyun, J.L., Gibson, M.J.S., King, C.M., and Moyle, L.C. (2019). A simple genetic architecture and low constraint allow rapid floral evolution in a diverse and recently radiating plant genus. New Phytol 223: 1009-1022.

van der Krol, A.R., Brunelle, A., Tsuchimoto, S., and Chua, N.H. (1993). Functional analysis of petunia floral homeotic MADS box gene pMADS1. Genes Dev 7: 1214-1228.

Kutschera, U., Bergfeld, R., and Schopfer, P. (1987). Cooperation of epidermis and inner tissues in auxin-mediated growth of maize coleoptiles. Planta 170: 168-180.

Kutschera, U. and Niklas, K.J. (2007). The epidermal-growth-control theory of stem elongation: an old and a new perspective. J. Plant Physiol. 164: 1395-1409.

Liao, Y., Smyth, G.K., and Shi, W. (2014). featureCounts: an efficient general purpose program for assigning sequence reads to genomic features. Bioinformatics 30: 923-930.

Love, M.I., Huber, W., and Anders, S. (2014). Moderated estimation of fold change and dispersion for RNA-seq data with DESeq2. Genome Biol 15: 550.

Martin, M. (2011). Cutadapt removes adapter sequences from high-throughput sequencing reads. EMBnet.journal 17: 10-12.

Meyerowitz, E.M. (1997). Genetic control of cell division patterns in developing plants. Cell 88: 299-308.

Morel, P., Chambrier, P., Boltz, V., Chamot, S., Rozier, F., Rodrigues Bento, S., Trehin, C., Monniaux, M., Zethof, J., and Vandenbussche, M. (2019). Divergent Functional Diversification Patterns in the SEP/AGL6/AP1 MADS-Box Transcription Factor Superclade. Plant Cell 31: 30333056. 
Moyroud, E. and Glover, B.J. (2017). The Evolution of Diverse Floral Morphologies. Curr. Biol. 27: R941-R951.

Perbal, M.C., Haughn, G., Saedler, H., and Schwarz-Sommer, Z. (1996). Non-cell-autonomous function of the Antirrhinum floral homeotic proteins DEFICIENS and GLOBOSA is exerted by their polar cell-to-cell trafficking. Development 122: 3433-3441.

Purugganan, M.D., Rounsley, S.D., Schmidt, R.J., and Yanofsky, M.F. (1995). Molecular evolution of flower development: diversification of the plant MADS-box regulatory gene family. Genetics 140: 345-356.

Quattrocchio, F., Verweij, W., Kroon, A., Spelt, C., Mol, J., and Koes, R. (2006). PH4 of Petunia is an R2R3 MYB protein that activates vacuolar acidification through interactions with basic-helixloop-helix transcription factors of the anthocyanin pathway. Plant Cell 18: 1274-1291.

Quattrocchio, F., Wing, J., van der Woude, K., Souer, E., de Vetten, N., Mol, J., and Koes, R. (1999). Molecular analysis of the anthocyanin2 gene of petunia and its role in the evolution of flower color. Plant Cell 11: 1433-1444.

Reale, L., Porceddu, A., Lanfaloni, L., Moretti, C., Zenoni, S., Pezzotti, M., Romano, B., and Ferranti, F. (2002). Patterns of cell division and expansion in developing petals of Petunia hybrida. Sex Plant Reprod 15: 123-132.

Reck-Kortmann, M., Silva-Arias, G.A., Segatto, A.L.A., Mader, G., Bonatto, S.L., and de Freitas, L.B. (2014). Multilocus phylogeny reconstruction: new insights into the evolutionary history of the genus Petunia. Mol Phylogenet Evol 81: 19-28.

Ren, H., Dang, X., Cai, X., Yu, P., Li, Y., Zhang, S., Liu, M., Chen, B., and Lin, D. (2017). Spatio-temporal orientation of microtubules controls conical cell shape in Arabidopsis thaliana petals. PLOS Genetics 13: e1006851.

Riechmann, J.L., Krizek, B.A., and Meyerowitz, E.M. (1996a). Dimerization specificity of Arabidopsis MADS domain homeotic proteins APETALA1, APETALA3, PISTILLATA, and AGAMOUS. Proc Natl Acad Sci U S A 93: 4793-4798.

Riechmann, J.L., Wang, M., and Meyerowitz, E.M. (1996b). DNA-binding properties of Arabidopsis MADS domain homeotic proteins APETALA1, APETALA3, PISTILLATA and AGAMOUS. Nucleic Acids Res 24: 3134-3141.

Rijpkema, A.S., Royaert, S., Zethof, J., Weerden, G. van der, Gerats, T., and Vandenbussche, M. (2006). Analysis of the Petunia TM6 MADS Box Gene Reveals Functional Divergence within the DEF/AP3 Lineage. The Plant Cell 18: 1819-1832.

Sandelin, A., Alkema, W., Engström, P., Wasserman, W.W., and Lenhard, B. (2004). JASPAR: an open-access database for eukaryotic transcription factor binding profiles. Nucleic Acids Res 32: D91-94.

Satina, S. and Blakeslee, A.F. (1941). Periclinal Chimeras in Datura Stramonium in Relation to Development of Leaf and Flower. American Journal of Botany 28: 862-871.

Satina, S., Blakeslee, A.F., and Avery, A.G. (1940). Demonstration of the Three Germ Layers in the Shoot Apex of Datura by Means of Induced Polyploidy in Periclinal Chimeras. American Journal of Botany 27: 895-905.

Savaldi-Goldstein, S. and Chory, J. (2008). Growth coordination and the shoot epidermis. Curr. Opin. Plant Biol. 11: 42-48.

Savaldi-Goldstein, S., Peto, C., and Chory, J. (2007). The epidermis both drives and restricts plant shoot growth. Nature 446: 199-202.

Scheres, B. (2001). Plant cell identity. The role of position and lineage. Plant Physiol 125: 112-114. Schwarz-Sommer, Z., Huijser, P., Nacken, W., Saedler, H., and Sommer, H. (1990). Genetic Control of Flower Development by Homeotic Genes in Antirrhinum majus. Science 250: 931-936. Silva, C.S., Puranik, S., Round, A., Brennich, M., Jourdain, A., Parcy, F., Hugouvieux, V., and Zubieta, C. (2015). Evolution of the Plant Reproduction Master Regulators LFY and the MADS 
Transcription Factors: The Role of Protein Structure in the Evolutionary Development of the Flower. Front Plant Sci 6: 1193.

Slater, G.S.C. and Birney, E. (2005). Automated generation of heuristics for biological sequence comparison. BMC Bioinformatics 6: 31.

Spelt, C., Quattrocchio, F., Mol, J.N.M., and Koes, R. (2000). anthocyanin1 of Petunia Encodes a Basic Helix-Loop-Helix Protein That Directly Activates Transcription of Structural Anthocyanin Genes. The Plant Cell 12: 1619-1631.

Stewart, R.N. and Burk, L.G. (1970). Independence of Tissues Derived from Apical Layers in Ontogeny of the Tobacco Leaf and Ovary. American Journal of Botany 57: 1010-1016.

Stormo, G.D. (2013). Modeling the specificity of protein-DNA interactions. Quant Biol 1: 115130.

Stuurman, J., Hoballah, M.E., Broger, L., Moore, J., Basten, C., and Kuhlemeier, C. (2004). Dissection of floral pollination syndromes in Petunia. Genetics 168: 1585-1599.

Terry, M.I., Pérez-Sanz, F., Díaz-Galián, M.V., Pérez de Los Cobos, F., Navarro, P.J., EgeaCortines, M., and Weiss, J. (2019). The Petunia CHANEL Gene is a ZEITLUPE Ortholog Coordinating Growth and Scent Profiles. Cells 8.

Theißen, G., Kim, J.T., and Saedler, H. (1996). Classification and phylogeny of the MADS-box multigene family suggest defined roles of MADS-box gene subfamilies in the morphological evolution of eukaryotes. J Mol Evol 43: 484-516.

Tornielli, G., Koes, R., and Quattrocchio, F. (2009). The Genetics of Flower Color. In Petunia: Evolutionary, Developmental and Physiological Genetics, T. Gerats and J. Strommer, eds (Springer: New York, NY), pp. 269-299.

Tröbner, W., Ramirez, L., Motte, P., Hue, I., Huijser, P., Lönnig, W.E., Saedler, H., Sommer, H., and Schwarz-Sommer, Z. (1992). GLOBOSA: a homeotic gene which interacts with DEFICIENS in the control of Antirrhinum floral organogenesis. EMBO J 11: 4693-4704. Urbanus, S.L., Dinh, Q.D.P., Angenent, G.C., and Immink, R.G.H. (2010). Investigation of MADS domain transcription factor dynamics in the floral meristem. Plant Signal Behav 5: 12601262.

Vandenbussche, M., Horstman, A., Zethof, J., Koes, R., Rijpkema, A.S., and Gerats, T. (2009). Differential recruitment of WOX transcription factors for lateral development and organ fusion in Petunia and Arabidopsis. Plant Cell 21: 2269-2283.

Vandenbussche, M., Janssen, A., Zethof, J., van Orsouw, N., Peters, J., van Eijk, M.J.T., Rijpkema, A.S., Schneiders, H., Santhanam, P., de Been, M., van Tunen, A., and Gerats, T. (2008). Generation of a 3D indexed Petunia insertion database for reverse genetics. Plant J 54: 1105-1114.

Vandenbussche, M., Zethof, J., Royaert, S., Weterings, K., and Gerats, T. (2004). The duplicated B-class heterodimer model: whorl-specific effects and complex genetic interactions in Petunia hybrida flower development. Plant Cell 16: 741-754.

Venail, J., Dell'olivo, A., and Kuhlemeier, C. (2010). Speciation genes in the genus Petunia. Philos Trans R Soc Lond B Biol Sci 365: 461-468.

Vincent, C.A., Carpenter, R., and Coen, E.S. (2003). Interactions between gene activity and cell layers during floral development. The Plant Journal 33: 765-774.

de Vlaming, P., Gerats, A.G.M., Wiering, H., Wijsman, H.J.W., Cornu, A., Farcy, E., and Maizonnier, D. (1984). Petunia hybrida: A short description of the action of 91 genes, their origin and their map location. Plant Mol Biol Rep 2: 21-42.

Wang, Z., Bai, L., Hsieh, Y.-J., and Roeder, R.G. (2000). Nuclear factor 1 (NF1) affects accurate termination and multiple-round transcription by human RNA polymerase III. The EMBO Journal 19: 6823-6832. 
bioRxiv preprint doi: https://doi.org/10.1101/2021.04.03.438311 this version posted April 4, 2021. The copyright holder for this preprint (which was not certified by peer review) is the author/funder, who has granted bioRxiv a license to display the preprint in perpetuity. It is made available under aCC-BY-NC-ND 4.0 International license.

Wuest, S.E., O’Maoileidigh, D.S., Rae, L., Kwasniewska, K., Raganelli, A., Hanczaryk, K., Lohan, A.J., Loftus, B., Graciet, E., and Wellmer, F. (2012). Molecular basis for the specification of floral organs by APETALA3 and PISTILLATA. Proc. Natl. Acad. Sci. U.S.A. 109: 13452-13457. Yadav, R.K., Tavakkoli, M., Xie, M., Girke, T., and Reddy, G.V. (2014). A high-resolution gene expression map of the Arabidopsis shoot meristem stem cell niche. Development 141: 2735-2744. Zenoni, S., Reale, L., Tornielli, G.B., Lanfaloni, L., Porceddu, A., Ferrarini, A., Moretti, C., Zamboni, A., Speghini, A., Ferranti, F., and Pezzotti, M. (2004). Downregulation of the Petunia hybrida alpha-expansin gene PhEXP1 reduces the amount of crystalline cellulose in cell walls and leads to phenotypic changes in petal limbs. Plant Cell 16: 295-308.

Zhong, J. and Preston, J.C. (2015). Bridging the gaps: evolution and development of perianth fusion. New Phytol. 208: 330-335. 